\title{
Down syndrome mouse models have an abnormal enteric nervous system
}

\author{
Ellen M. Schill, ${ }^{1,2}$ Christina M. Wright, ${ }^{2}$ Alisha Jamil, ${ }^{2}$ Jonathan M. LaCombe, ${ }^{3}$ Randall J. Roper, ${ }^{3}$ \\ and Robert $\mathrm{O}$. Heuckeroth ${ }^{2}$ \\ 'Department of Pediatrics, Washington University School of Medicine, St. Louis, Missouri, USA. ²Department of Pediatrics, \\ Children's Hospital of Philadelphia Research Institute and Perelman School of Medicine at the University of Pennsylvania, \\ Abramson Research Center, Philadelphia, Pennsylvania, USA. ${ }^{3}$ Department of Biology, Indiana University-Purdue \\ University Indianapolis, Indianapolis, Indiana, USA
}

Children with trisomy 21 (Down syndrome [DS]) have a 130-fold increased incidence of Hirschsprung disease (HSCR), a developmental defect in which the enteric nervous system (ENS) is missing from the distal bowel (i.e., distal bowel is aganglionic). Treatment for HSCR is surgical resection of aganglionic bowel, but many children have bowel problems after surgery. Postsurgical problems, such as enterocolitis and soiling, are especially common in children with DS. To determine how trisomy 21 affects ENS development, we evaluated the ENS in 2 DS mouse models, Ts65Dn and Tc1. These mice are trisomic for many chromosome 21 homologous genes, including Dscam and Dyrk1a, which are hypothesized to contribute to HSCR risk. Ts65Dn and Tc1 mice have normal ENS precursor migration at E12.5 and almost normal myenteric plexus structure as adults. However, Ts65Dn and Tc1 mice have markedly reduced submucosal plexus neuron density throughout the bowel. Surprisingly, the submucosal neuron defect in Ts65Dn mice is not due to excess Dscam or Dyrk1a, since normalizing copy number for these genes does not rescue the defect. These findings suggest the possibility that the high frequency of bowel problems in children with DS and HSCR may occur because of additional unrecognized problems with ENS structure.

Authorship note: EMS and CMW contributed equally to this work.

Conflict of interest: The authors have declared that no conflict of interest exists.

Copyright: (c) 2019, American Society for Clinical Investigation.

Submitted: September 4, 2018

Accepted: April 17, 2019

Published: June 6, 2019.

Reference information: JCI Insight. 2019;4(11):e124510. https://doi. org/10.1172/jci.insight.124510.

\section{Introduction}

Children with Down syndrome (DS, trisomy 21) have high rates of congenital heart disease, central nervous system dysfunction (i.e., behavioral and emotional problems, Alzheimer's disease, seizures), vision problems, hearing loss, infections, hypothyroidism, leukemia, poor muscle tone, atlantoaxial dysplasia (an upper spine defect), dental problems, and gastrointestinal disease (duodenal atresia, anal atresia, celiac disease, and Hirschsprung disease [HSCR]) (1). Even without serious bowel disease, children with DS commonly have chronic constipation or diarrhea $(2,3)$. One major challenge is defining which genes on human chromosome 21 (Hsa21) cause each disease manifestation and what structural and functional problems underlie symptoms. Here, we examine how trisomy affects enteric nervous system (ENS) development and bowel function using 2 DS mouse models.

The ENS is a complex network of neurons and glia that autonomously controls most aspects of bowel function (4-6). Abnormal ENS development can be life-threatening, especially when the ENS is missing from the distal bowel, a problem called HSCR. The ENS is derived from diverse cell sources. Most ENS precursors are enteric neural crest-derived cells (ENCDC) originating from somite levels 3-7. These ENCDC invade the foregut by mouse E9.5, proliferate, and migrate distally to fully colonize developing bowel by E14.5. Additional ENCDC in esophagus and stomach are derived from somite levels 1-2, while sacral neural crest and pelvic Schwann cell derivatives contribute to ENS in descending colon and rectum $(7,8)$. Recent papers suggest cells of endodermal origin also contribute to the ENS (9) and that there is continuous ENS replacement during postnatal life (10). Independent of cell origin, initial longitudinal colonization of the bowel by ENCDC occurs in the region of future myenteric plexus. After longitudinal migration is complete, a subset of ENS precursors migrates inward toward the lumen to form the submucosal plexus, in a process called radial migration $(5,11,12)$. These inner submucosal plexus and outer myenteric plexus cells constitute the ENS and work together to regulate fluid secretion, blood flow, and motility needed for survival.

HSCR occurs in 1 in 5000 live births (13), but, strikingly, HSCR has an incidence of about 1 in 40 in children with DS $(14,15)$. The primary problem in HSCR is that migrating ENCDC fail to completely colonize 
distal bowel, leaving a region of aganglionic bowel that tonically contracts and does not have normal propulsive motility, leading to functional obstruction. Diverse HSCR symptoms and data from animal models suggest additional ENS defects may occur in children with HSCR (16-19). Standard HSCR treatment is surgical resection of aganglionic bowel and reanastomosis of ENS-containing proximal bowel to near the anal verge. While this "pull-through" surgery is lifesaving, many children experience problems after surgery, including enterocolitis, constipation, and fecal incontinence $(13,20)$. These problems are especially common in children with DS $(21,22)$. We suspect some postsurgical problems result from subtle defects in ENS structure or function, including altered neuron number, connectivity, and differentiation, but methods to identify these defects in human bowel are not well established. The higher prevalence of HSCR in children with DS has also not been explained, although it is likely due to overexpression of one or more Hsa21 genes.

One longstanding hypothesis is that overexpression of DS cell adhesion molecule (DSCAM) explains increased HSCR risk in people with DS (23). Consistent with this hypothesis, DSCAM is 1 of approximately 160 genes in the HSCR-associated critical region in individuals with rare partial trisomy 21 (24). Furthermore, DSCAM mRNA is present in migrating ENS precursors (25), and recent genetic studies identified selected DSCAM SNPs at increased frequency in individuals with $\operatorname{HSCR}(23,26)$. Additionally, DSCAM is a receptor for netrin $(27,28)$, a protein that attracts ENCDC to submucosal plexus (11). Despite these suggestive data, DSCAM function in ENS development has not been evaluated.

Another HSCR critical region-associated gene identified in partial trisomy is dual-specificity tyrosine phosphorylation-regulated kinase (DYRK1A) (24). DYRK1A is expressed in adult human colon ganglia (Human Protein Atlas) (29) and Dyrk1a is transcribed in mouse ENS precursors (GenePaint) (30). DYRK1A phosphorylates and activates GLI1 (31), an important Hedgehog pathway protein whose overexpression is implicated in some human HSCR cases $(32,33)$. In brain, DYRK1A overexpression lengthened G1, leading to fewer cell divisions and cortical neuron deficits persisting into adulthood (34-36). However, the role of DYRK1A in ENS development has not been explored.

To examine how trisomy predisposes to HSCR and other ENS defects, we studied 2 commonly used mouse trisomy 21 models, Ts65Dn and Tc1. Neither model perfectly recapitulates DS since Hsa21 has mouse orthologs on parts of mouse chromosomes (Mmu) 16 (28 Mb), $17(1.5 \mathrm{Mb})$, and 10 $(3 \mathrm{Mb})$. Ts65Dn $[\mathrm{B} 6 \mathrm{EiC} 3 \mathrm{Sn}$ a/A-Ts $(17<16>) 65 \mathrm{Dn} / \mathrm{J}]$, the most commonly studied mouse DS model (37), has a freely segregating chromosome that includes the distal end of Mmu16 attached to the centromeric end of Mmu17 (including 25 protein coding Mmu17 genes). Ts65Dn mice are trisomic for approximately $55 \%$ of protein-coding Hsa21 orthologous genes (38), including HSCR risk candidate genes Dscam and Dyrk1a (24). The resulting partial trisomy has been used to model many molecular, anatomic, and behavioral aspects of DS in mice, but an ENS phenotype in this model has not been reported (37, 39-45). Ts65Dn mice might be a particularly good HSCR model, since they have 3 copies of almost all genes identified in the HSCR critical region in humans (24). Another DS mouse model is the B6129S-Tc(HSA21)1TybEmcf/J line known as Tc1 $(46,47)$. This transchromosomal model has most of Hsa21 integrated into its genetic material, including the HSCR critical region containing DSCAM and DYRK1A. This model has limitations, including mosaicism of the human chromosome (with retention of $\mathrm{Hsa} 21$ in as few as $49 \%$ of cells for some organs, ref. 46), interspecies gene differences, duplications, deletions, and structural rearrangements (47). Because Ts65Dn and Tc1 have 3 copies of some but not all of the same genes, comparing outcomes in these models allows refinement of gene regions that lead to DS-associated bowel phenotypes (24).

Here, we show that Ts65Dn and Tc1 mice have neurons throughout the bowel, including in distal colon, and that longitudinal migration of ENCDC during development is normal. However, adult trisomic Ts65Dn mice have reduced neuron density in distal colon, and both Ts65Dn and Tc1 mice have marked submucosal plexus hypoganglionosis. Reduced submucosal neuron density is not accompanied by altered neuron subtype ratios and the defect is not corrected by normalizing gene copy number for Dscam or Dyrk1a in Ts65Dn trisomic mice. Although small bowel motility in Ts65Dn and Tc1 mice is normal, colon motility and stooling patterns in Ts65Dn trisomic mice are abnormal, consistent with enteric neuron defects. These results suggest that genes present in triplicate in 2 mouse models for DS are important for submucosal plexus formation and for bowel function. Our results challenge the longstanding hypothesis that Dscam is important for ENS precursor migration down developing bowel and may provide insight into the increased incidence of postsurgical problems in children with DS and HSCR. 


\section{Results}

Ts65Dn and Tc1 mice have normal-appearing midgestation ENS. Because human DS increases HSCR risk 130fold, we hypothesized that the ENS in Ts65Dn and Tc1 mice might be abnormal. Aganglionosis, however, would be uncommon in a mouse completely recapitulating human DS, since only about 1 in 40 children with DS has HSCR (14). Unsurprisingly (since aganglionosis is fatal), adult Ts65Dn and Tc1 trisomic mice analyzed all had neurons in the distal colon (Ts65Dn: $n=6$, Tc1: $n=7$ ). We also did not detect statistically significant death by the time of weaning with HSCR-like disease tend to die $\left(43.75 \%\right.$ Ts $65 \mathrm{Dn}, P=0.4786, \chi^{2}$ test, $n=36$ [euploid] and $n=28$ [Ts65Dn]; 42.7\% Tc1, $P=0.106, \chi^{2}$ test, $n=71$ [euploid] and $n=53$ [Tc1]) (48, 49), although larger cohorts of Ts65Dn and Tc1 mice have shown significant reductions of trisomic offspring $(46,50)$. To determine if trisomy slows ENCDC migration through fetal bowel or reduces neuron density, we stained E12.5 hindgut with TuJ1, an antibody against neuron-specific $\beta-3$ tubulin (Figure 1, A-D). We found the extent of bowel colonization by ENCDC was normal compared with age- and strain-matched littermate controls (Figure 1, I and J). Specifically, the entire small bowel and approximately 65\% of colon were colonized by ENCDC in each mouse strain. $\mathrm{TuJ} 1^{+}$and $\mathrm{HuC} / \mathrm{D}^{+}$enteric neurons were also present at normal density at the migration wavefront (i.e., most distal $500 \mu \mathrm{m}$ of colon with neurons) in E12.5 Ts65Dn and $\mathrm{Tc} 1$ mice (Figure 1, E-H, K, and L). As an alternative approach to evaluate ENCDC migration, we cultured E12.5 mid-gut slices overnight on fibronectin-coated dishes (Figure 1M). ENS precursors migrated from gut slices in response to the RET ligand glial cell-derived neurotrophic factor (GDNF). Consistent with in vivo data, the distance ENCDC migrated from gut slices was normal in Ts65Dn and Tc1 mice (Figure 1, N and O). Finally, to more closely recapitulate human HSCR, where inactivating RET receptor tyrosine kinase risk alleles are common $(15,51)$, we analyzed Ts65Dn; Ret $^{+/-}$mice but also found normal bowel colonization by ENCDC at E12.5 (Figure 1P). Collectively, these data suggest that extent of colonization of fetal bowel by ENCDC and efficiency of ENCDC migration in vitro are normal in Ts65Dn and Tc1 mice.

Ts65Dn and Tc1 trisomic mice have reduced submucosal plexus neuron density. The ENS is complex, with many cell types in the myenteric and submucosal plexus (52). To evaluate Ts65Dn and Tc1 ENS in more detail, whole mount preparations from 80- to 120-day bowels were stained with TuJ1 and HuC/D antibodies (Figure 2, A-L and S- $\left.\mathrm{D}^{\prime}\right)$. Quantitative analysis showed normal density of myenteric neurons in small bowel and mid-colon of Ts65Dn and Tc1 mice (Figure 2, M, O, E', and $\mathrm{G}^{\prime}$ ). Intriguingly, myenteric plexus neuron density was reduced in distal colons of Ts65Dn, but not Tc1, adult mice (Figure 2, Q and I', and Table 1).

In contrast to myenteric plexus, submucosal neuron density was markedly reduced in many bowel regions of Ts65Dn animals, including small bowel, mid-colon, and distal colon (Figure 2, N, P, and R, and Table 1). Tc1 mice also had reduced submucosal neuron density in small bowel (Figure $2 \mathrm{~F}^{\prime}$ and Table 1), and the mean distal colon submucosal neuron density was reduced $35 \%(P=0.053$ compared with controls) (Figure 2J' and Table 1$)$. In contrast, submucosal neuron density was normal in the mid-colon (Figure $2 \mathrm{H}^{\prime}$ ) of Tc1 mice. Neuron density also differed between euploid control animals of different stains, consistent with prior reports that ENS structure and bowel motility are strain dependent (53). These data suggest partial trisomy mimicking human DS causes submucosal plexus hypoganglionosis in mice. Because Ts65Dn mice have a more dramatic ENS phenotype than Tc1 mice, and since Tc1 mice have mosaicism, our further analyses focused primarily on Ts65Dn mice.

Multiple submucosal neuron subtypes are reduced in Ts65Dn trisomic mice. The ENS has diverse neuron subtypes with various functions (52), including smooth muscle contraction and relaxation, regulation of fluid secretion, and vasodilation. Reduced submucosal neuron density might reflect loss of single submucosal neuron subpopulations or reductions in many neuron types. To determine if specific neuron subtypes are absent in Ts65Dn submucosal plexus, whole mount adult small bowel preparations were stained with antibodies against $\mathrm{HuC} / \mathrm{D}$, vasoactive intestinal peptide (VIP), somatostatin (SST), and tyrosine hydroxylase (TH). This permits analysis of VIP/TH secretomotor neurons (that also express neuropeptide $\mathrm{Y}$ and calretinin), VIP vasodilator neurons (that also express neuropeptide $\mathrm{Y}$ and calretinin), SST secretomotor neurons (that also express choline acetyltransferase [ChAT], calcitonin generelated peptide, and calretinin), and neurons with unknown targets (that express ChAT alone or neither ChAT nor VIP, hereafter referred to as SST-VIP neurons) (54). Quantitative analysis showed the percentage of $\mathrm{SST}^{+}, \mathrm{TH}^{+}, \mathrm{VIP}^{+}$, and SST-VIP neurons compared with total neurons $\left(\mathrm{HuC} / \mathrm{D}^{+}\right)$was statistically equivalent in euploid and Ts65Dn mice (Figure 3, A-O). This suggests that all submucosal neuron populations were reduced in Ts65Dn animals. However, analysis of neurons per unit area showed statistically significant reductions only for VIP (33\% reduced; $P=0.024)$ and SST-VIP $(52 \%$ reduced; $P=0.032)$ submucosal neurons, suggesting a greater loss of these neuron subtypes (Figure 3P). 

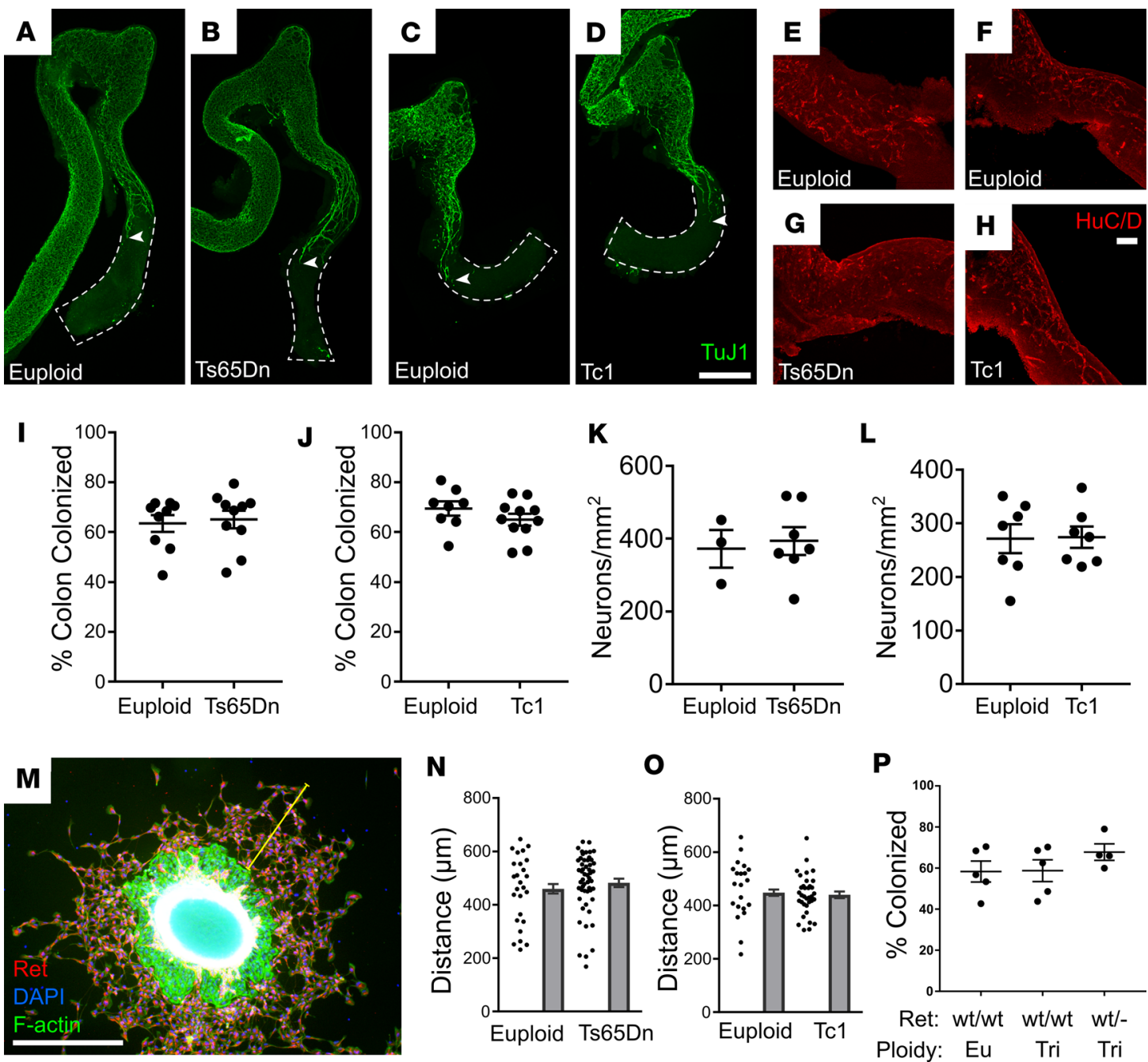

Figure 1. Tc1 and Ts65Dn mice have normal bowel colonization by ENS precursors at E12.5. (A-D) Ts65Dn and Tc1 euploid and trisomic E12.5 colon and distal small bowel were stained using Tuj1 antibody that marks early and mature neurons. Maximum intensity projections of confocal Z-stacks are shown. White arrowheads indicate the position of most caudal TuJ1 immunoreactive neuronal process (green). Scale bar: $500 \mu m$. (E-H) High-resolution images show HuC/ $\mathrm{D}^{+}$cell bodies (red) in hindgut in Ts65Dn (E and $\left.\mathbf{F}\right)$ and Tc1 (G and $\left.\mathbf{H}\right)$ lineage mice. Scale bar: $100 \mu \mathrm{m}$. (I and J) Percentage of colon colonized by ENCDC relative to total colon length for Ts65Dn (I; $P=0.653$, Mann-Whitney rank sum test [MWRST], $n=9$ [WT] and 10 [Ts65Dn]) and Tc1 (J; $P=0.24, t$ test, $n=9$ [WT] and 11 [Tc1]) mice. (K and L) Mean HuC/D+ neuron density in most distal $500 \mu \mathrm{m}$ of colonized bowel for Ts65Dn (K, $P=0.76 ; t$ test, $n=3$ [WT], $n=7$ [Ts65Dn]) and Tc1 (L, $P=0.94, t$ test, $n=7$ [WT], $n=8$ [Tc1]) mice. (M-0) Small bowel slices from E12.5 Ts65Dn and Tc1 mice were plated on fibronectin-treated chamber slides. CDNF was added 4 hours later. After an additional 16 hours in GDNF-containing media, slices were fixed and the distance from the farthest-migrated ENCDC to the slice edge (yellow line) was measured and averaged over 4 quadrants. (M) Representative image from slice culture after staining for RET (to identify ENCDC, red), phalloidin (which stains F-actin, green), and DAPI (nuclear stain, blue). (N and $\mathbf{0}$ ) Ts65Dn (N, $P=0.436$, MWRST, $n=26$ [euploid] and 52 [Ts65Dn]) and Tc1 (0, $P=0.385, t$ test, $n=21$ [euploid] and 35 [Tc1]) animals had similar ENCDC migration distance to euploid animals. (P) Ret heterozygosity did not affect migration of Ts65Dn ENCDC ( $P=0.38$, ANOVA, $n=5$ [Euploid, Ret $\left.{ }^{+/+}\right], n=5\left[\right.$ Ts65Dn, Ret $\left.{ }^{+/+}\right]$, and $n=4\left[\right.$ Ts65Dn, Ret $\left.t^{+/}\right]$).

Since subtype alterations may occur without neuron loss, we additionally examined 2 major neuron subclasses in the myenteric plexus of adult Ts65Dn mice. We found a normal density of small bowel excitatory $\left(\right.$ calretinin $^{+}$) and inhibitory (nitric oxide synthase ${ }^{+}$) motor neurons (Figure 4, A-J). Density of SOX $10^{+}$glia within adult small bowel myenteric layers was also normal (Figure 4, K-M).

To assess whether Ts65Dn mice have altered villus innervation, we immunostained villi from midsmall intestine using TuJ1 to label neurites and counted nerve fibers bisecting a line at mid-villus height (Figure 5, A and B). Neurite numbers were equal in euploid and Ts65Dn mice (Figure 5C), despite approximately $40 \%$ reductions in submucosal neuron density in this region.

Reduced submucosal plexus neuron density in Ts65Dn mice is not explained by altered ENCDC proliferation, apoptosis, or glial lineage commitment. To define cellular mechanisms that could reduce submucosal 

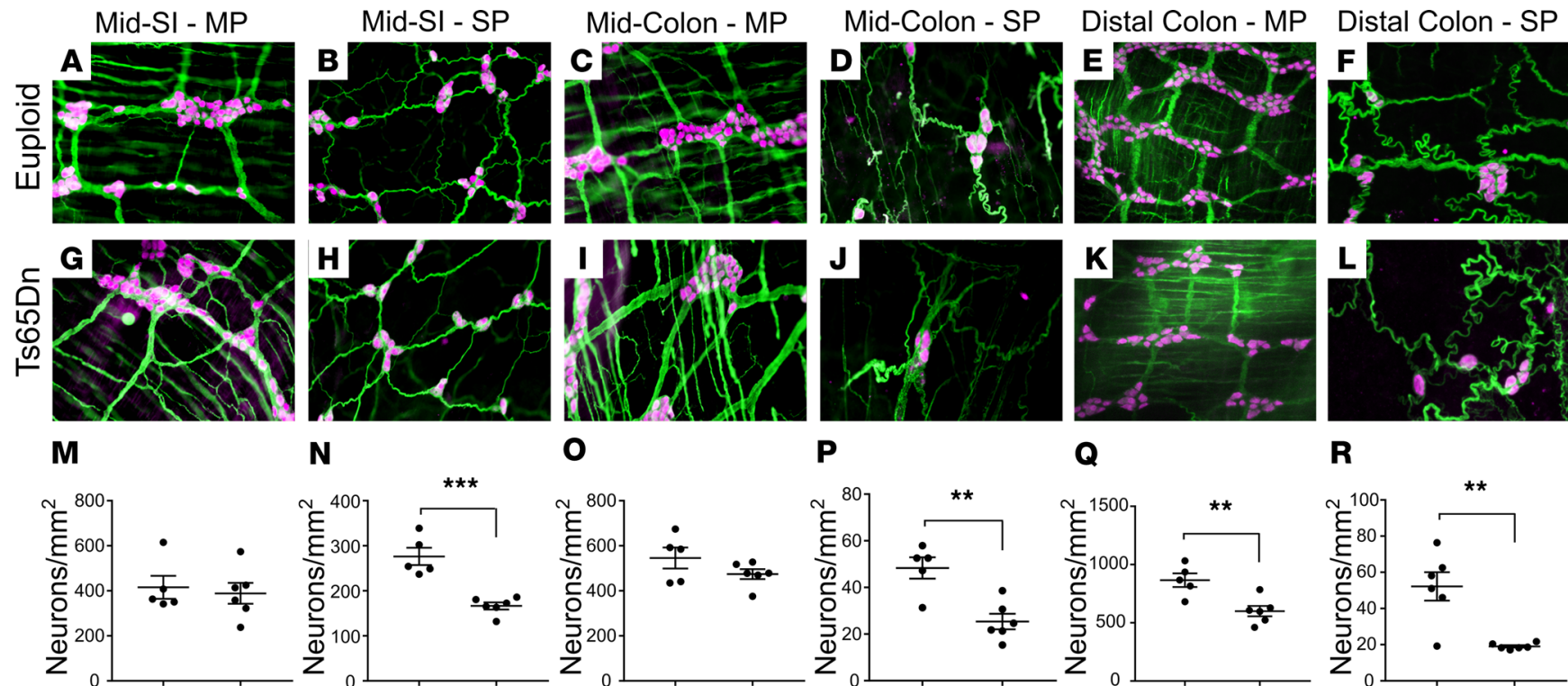

0

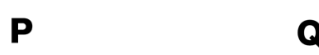

\section{.}
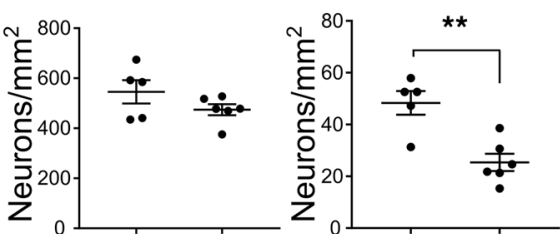

Eu Tri

Eu Tri
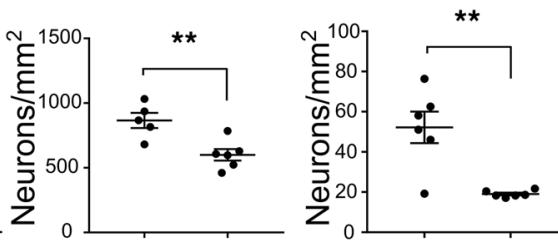

Eu Tri

Eu Tri

Eu Tri
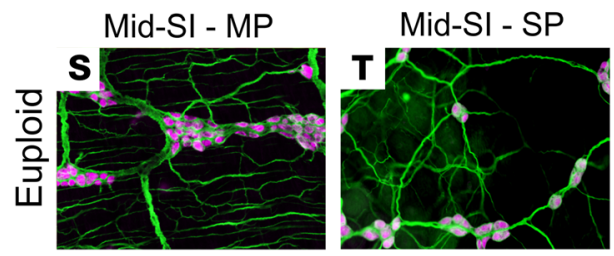

Mid-Colon - MP
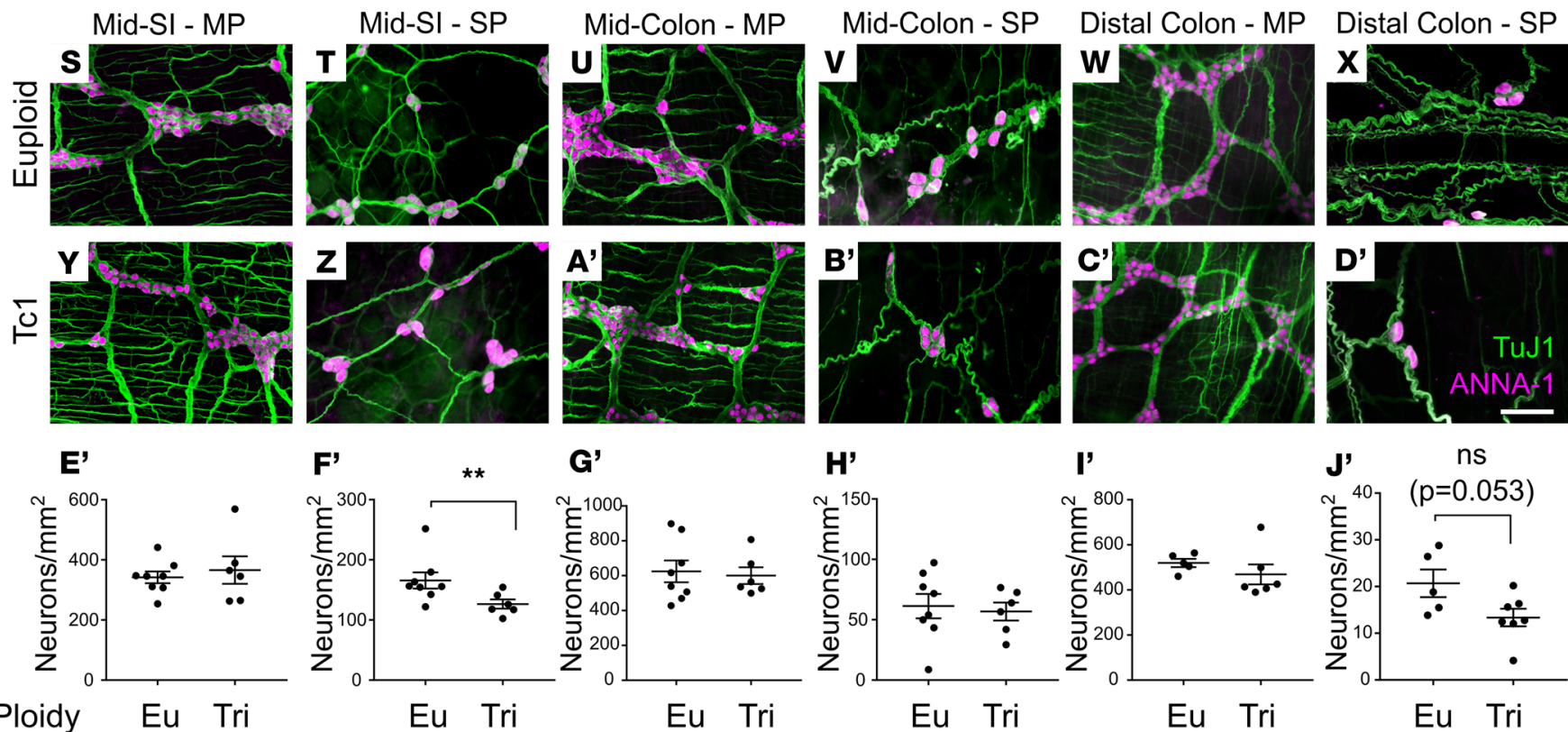

G'

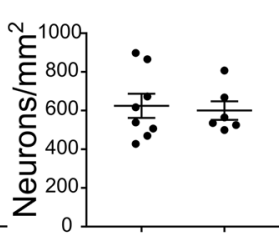

Eu Tri

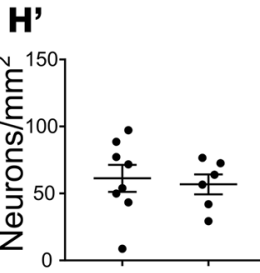

Eu Tri

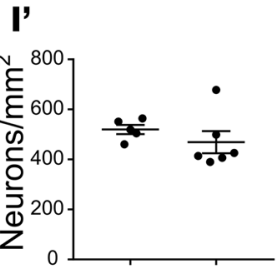

Eu Tri

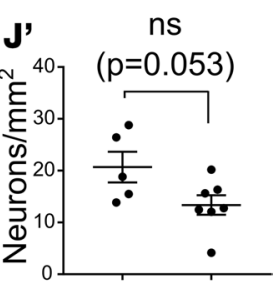

Eu Tri

Figure 2. Tc1 and Ts65Dn mice have hypoganglionosis, especially in submucosal plexus. (A-L) Ts65Dn and (S-D') Tc1 trisomic and euploid myenteric and submucosal plexuses were stained with TuJ1+ (green) and HuC $/ \mathbf{D}^{+}$(magenta) antibodies. (A, C, E, G, I, K, S, U, W, Y, A', and C') Myenteric plexus (MP). (B, D, F, H, J, L, T, V, X, Z, B', and D') Submucosal plexus (SP). (M-R) Quantitative analysis of neuron density for euploid and Ts65Dn mice (see also Table 1 for quantitative data and statistical tests). (E'-J') Quantitative analysis of neuron density for euploid and Tc1 mice (see also Table 1 for quantitative data and statistical tests). Scale bar: $100 \mu \mathrm{m} .{ }^{* *} P<0.01,{ }^{* *} P<0.001$.

neuron density in Ts65Dn mice, we examined P1 small bowel because submucosal plexus is not fully populated in mice prior to birth and many submucosal neuron precursors exit the cell cycle at P1 (55, 56). At this age, TuJ1 antibody stains neurons and committed neuronal precursors, while SOX10 is expressed in enteric glia and uncommitted neuron/glia precursors. Analysis of submucosal plexus showed $\mathrm{TuJ}^{+}$cells were already less abundant in Ts65Dn mice by P1 (Figure 6, A-D). In contrast, 5-ethynyl-2-deoxyuridine (EdU) staining showed normal proliferation rates for $\mathrm{TuJ}^{+}$and SOX10 submucosal plexus cells (Figure 6, A-C, E, and F). Ki67 antibody, which labels proliferating cells in all cell cycle phases, also showed normal percentages of cycling TuJ1+ and SOX $10^{+}$cells in P1 Ts65Dn submucosal plexus (Figure 6, G-I, K, and L). Collectively, these data suggest reduced precursor pro- 
Table 1. Quantitative neuron density data

\begin{tabular}{|c|c|c|c|c|c|}
\hline & \multicolumn{2}{|c|}{ Cell density (cells/mm²) } & \multirow[t]{2}{*}{$\%$ Change } & \multirow[t]{2}{*}{$P$ value } & \multirow[t]{2}{*}{ Test } \\
\hline Ts65Dn & Euploid & Trisomy & & & \\
\hline Small intestine myenteric plexus & $415.4 \pm 51.2$ & $388.5 \pm 46.3$ & $-6.5 \%$ & 0.7049 & $t$ test \\
\hline Small intestine submucosal plexus & $276.2 \pm 19.2$ & $166.4 \pm 7.8$ & $-39.8 \%$ & 0.0003 & $t$ test \\
\hline Mid-colon submucosal plexus & $48.3 \pm 4.6$ & $25.4 \pm 3.3$ & $-47.5 \%$ & 0.0025 & $t$ test \\
\hline Distal colon myenteric plexus & $866 \pm 58.9$ & $599.9 \pm 44.7$ & $-30.7 \%$ & 0.0052 & $t$ test \\
\hline Distal colon submucosal plexus & $52.2 \pm 7.9$ & $19.0 \pm 0.7$ & $-63.5 \%$ & 0.0018 & $t$ test \\
\hline Small intestine myenteric plexus & $341.6 \pm 19.5$ & $365.9 \pm 45.8$ & $+7.1 \%$ & 0.6006 & $t$ test \\
\hline Small intestine submucosal plexus & $165.6 \pm 13.6$ & $126.4 \pm 7.6$ & $-23.7 \%$ & 0.0093 & MWRST \\
\hline Mid-colon myenteric plexus & $624.6 \pm 62.5$ & $600.2 \pm 47.8$ & $-3.9 \%$ & 0.7759 & $t$ test \\
\hline Mid-colon submucosal plexus & $61.3 \pm 10.1$ & $56.8 \pm 7.5$ & $-7.3 \%$ & 0.7419 & $t$ test \\
\hline Distal colon myenteric plexus & $519.5 \pm 18.3$ & $468.8 \pm 44.6$ & $-9.8 \%$ & 0.3544 & $t$ test \\
\hline Distal colon submucosal plexus & $20.7 \pm 3.0$ & $13.4 \pm 1.9$ & $-35 \%$ & 0.0533 & $t$ test \\
\hline
\end{tabular}

liferation is unlikely to account for reduced submucosal neuron density in Ts65Dn mice. To evaluate cell death, we stained $\mathrm{P} 1$ submucosa for activated caspase- 3 and $\mathrm{TuJ} 1^{+}$but only found rare $\mathrm{TuJ} 1^{+}$ caspase $-3^{+}$cells in euploid or trisomic mice (Figure 7, A-D). This suggests that increased cell death is unlikely to explain reduced submucosal neuron density in Ts65Dn ENS. We also did not find evidence that ENCDC were selectively converted to enteric glia. Density of mature glial lineage cells (defined as SOX $10^{+} \mathrm{Ki}^{-}$) was the same in Ts65Dn trisomic and WT submucosal plexus at P1 (Figure 6, G-J) and in adults (SOX10 $0^{+}$cells; Figure 7, E-H). Interestingly, although the percentage of SOX $10^{+}$cells that were EdU ${ }^{+}$(Figure 6F) or $\mathrm{Ki}^{+} 7^{+}$(Figure 6L) was normal in Ts65Dn mice, the density of SOX10 ${ }^{+} \mathrm{Ki6} 7^{+}$ cells was slightly (17\%) reduced in P1 trisomic mouse submucosal plexus (Figure $6 \mathrm{~J}$ ). A reduced density of cycling cells without a change in percentage of cycling cells suggests fewer precursors recently migrated from outer bowel wall to submucosal plexus, but we have not found a direct way to test this.

Trisomy alters bowel motility and stooling patterns. To determine if trisomic mice have abnormal bowel motility, we assessed small bowel transit by gavage-feeding adult Ts65Dn and Tc1 mice FITC-dextran (57). FITC-dextran in each bowel segment was measured 2 hours (Ts65Dn) or 1 hour (Tc1) after gavage (Figure 8, $\mathrm{A}$ and $\mathrm{B}$ ). The geometric mean for FITC-dextran transit through the bowel showed no difference between euploid and trisomic mice (Figure 8, C and D), suggesting normal small bowel motility. We also evaluated colon motility by bead expulsion assay (57) (Figure 8, E and F). For this and subsequent functional experiments, Ts65Dn mice were on a mixed genetic background (B6EiC3Sn $\times$ C57BL/6J). Although mean bead expulsion time in Ts65Dn animals was longer than in euploid animals, this did not reach statistical significance (Figure 8E). One data point was identified as a clear outlier using Grubb's and ROUT outlier tests. In this animal, which was tested 3 times, expulsion times were 99 seconds, 1758 seconds, and 91 seconds, suggesting colon injury on the second testing day. When this data point is excluded, the $P$ value is statistically significant $(P=0.0117)$, suggesting slower colonic bead expulsion in Ts65Dn mice compared with euploid mice. In contrast, Tc1 and control mice had similar colonic bead expulsion times (Figure 8F).

To further characterize colon motility, we generated spatiotemporal maps from Ts65Dn colons maintained in a warmed, oxygenated organ bath with 2-cm height of Krebs-Ringers solution generating intraluminal pressure. Ts65Dn colons exhibited neurally mediated colonic migrating motor complexes (CMMCs) that propagated down the bowel in a rostro-caudal direction (Figure $8, \mathrm{G}$ and $\mathrm{H}$, and Supplemental Videos 1 and 2; supplemental material available online with this article; https://doi. org/10.1172/jci.insight.124510DS1). The average frequency of CMMCs over an hour was similar for euploid and Ts65Dn mice (Figure 8I; $P=0.30$, Mann-Whitney rank sum test [MWRST], $n=8$ euploid and $n=7$ trisomy). Collectively, these data suggest that Ts65Dn mice have normal small bowel transit of luminal contents but reduced colon motility in vivo (based on FITC-dextran and colonic bead expulsion tests). However, the Ts65Dn colon generates normal patterns of contractility in vitro, suggesting there are not gross disturbances in colon ENS circuitry. 

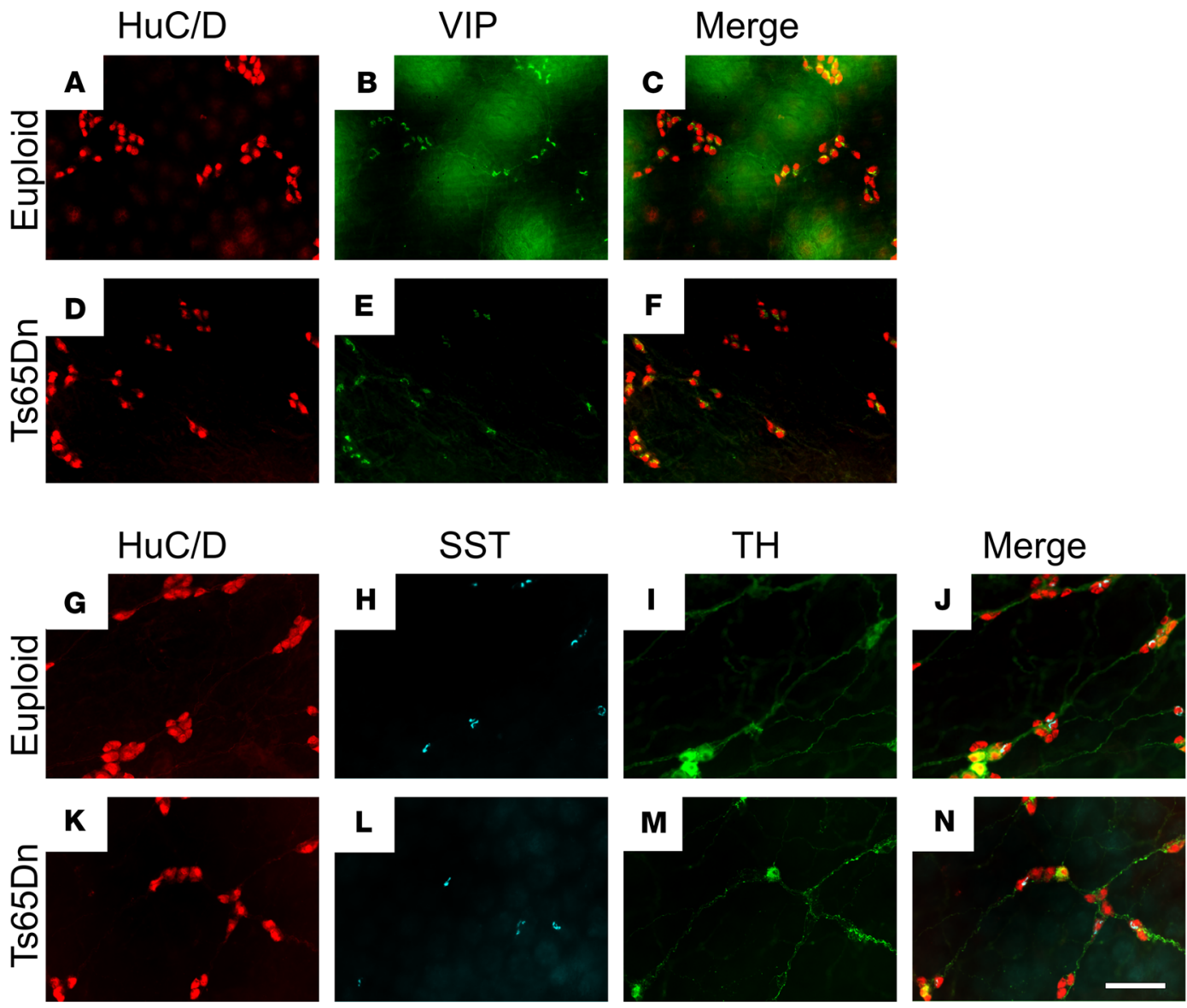

o

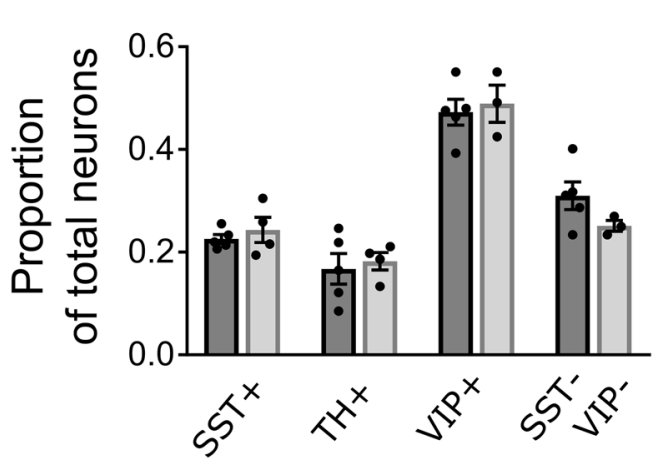

$\mathbf{P}$

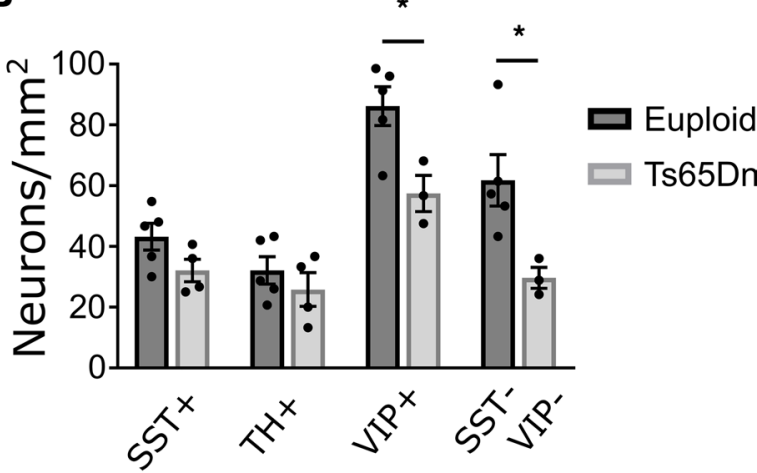

Figure 3. Analysis of subtypes of submucosal neurons in Ts65Dn adult mice. (A-N) Euploid and Ts65Dn adult submucosal plexuses from small bowel were stained for $\mathrm{HuC/D}$ (red) and VIP (green) (A-F) or HuC/D (red), SST (cyan), and TH (green) (G-N). Scale bar: $100 \mu \mathrm{m}$. (0) Proportion of neuron subtypes relative to total $\mathrm{HuC} /$ $D^{+}$cells (SST: $P=0.477$, $t$ test, $n=5$ [euploid] and $n=4$ [Ts65Dn]; TH: $P=0.905$, MWRST, $n$ $=5$ [euploid] and $n=3$ [Ts65Dn]; VIP: $P=0.712$, $t$ test, $n=5$ [euploid] and $n=3$ [Ts65Dn]; SST-VIP: $P=0.164, t$ test, $n=5$ [euploid] and $n=3$ [Ts65Dn]). Note that $\mathrm{TH}^{+}$neurons are a subset of VIP+ neurons. (P) Absolute neuron density per $\mathrm{mm}^{2}$ for neuron subtypes (SST: $P=0.104$, $t$ test, $n=5$ [euploid] and $n=4$ [Ts65Dn]; TH: $P=0.40, t$ test, $n$ $=5$ [euploid] and $n=3$ [Ts65Dn]; VIP: $P=0.024$, $t$ test, $n=5$ [euploid] and $n=3$ [Ts65Dn]; SSTVIP: $P=0.032, t$ test, $n$ $=5$ [euploid] and $n=3$ [Ts65Dn]). ${ }^{*} P<0.05$.

Since submucosal plexus regulates bowel water and electrolyte secretion $(58,59)$, we assessed stool mass and water content in trisomic and euploid mice. Stool was collected for 1 hour. Wet weight per stool pellet was reduced in Ts65Dn mice on a B6EiC3Sn background $(P=0.003)$ but was normal for Ts65Dn mice on a mixed (B6EiC3Sn $\times$ C57BL/6) background (Figure 8J). Per stool weight was normal in Tc1 mice (Figure 8J). Both Ts65Dn and Tc1 mice had normal stool water content (Figure 8K). These data suggest trisomy may affect stool volume but only in Ts65Dn mice on specific genetic backgrounds.

Ts65Dn submucosal plexus defects are not due to excess Dscam or Dyrk1a. Defining molecular mechanisms that reduce submucosal neurons in trisomic animals is not trivial. Ts65Dn mice have 3 copies of part of Mmu16. Tc1 mice are mosaic for an extra human chromosome that contains most Hsa21 genes. Since Ts65Dn and Tc1 mice both have reduced submucosal neurons, we hypothesize that critical regulators of submucosal neuron number must be encoded in shared trisomic genes. Unfortunately, over 60 genes are shared in Ts65Dn and Tc1 trisomic regions. We decided to test the hypothesis that excess DSCAM or DYRK1A causes submucosal neuron hypoganglionosis in trisomic mice for the following reasons. DSCAM and DYRK1A are encoded in a 

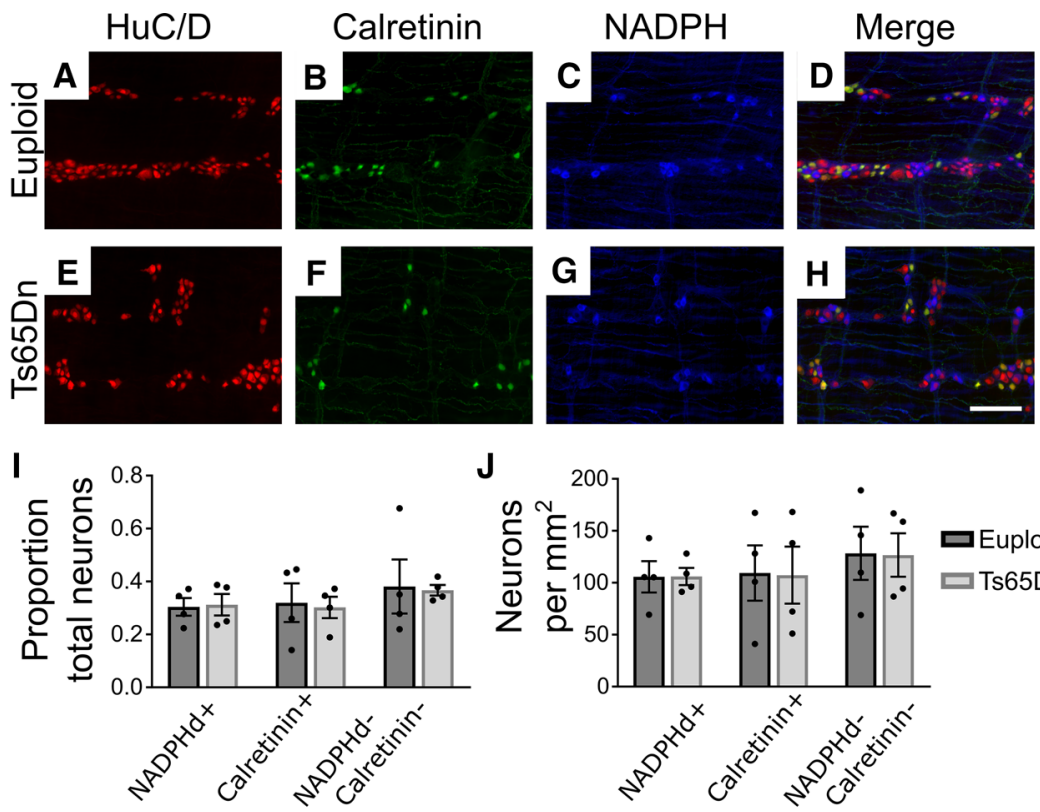

J
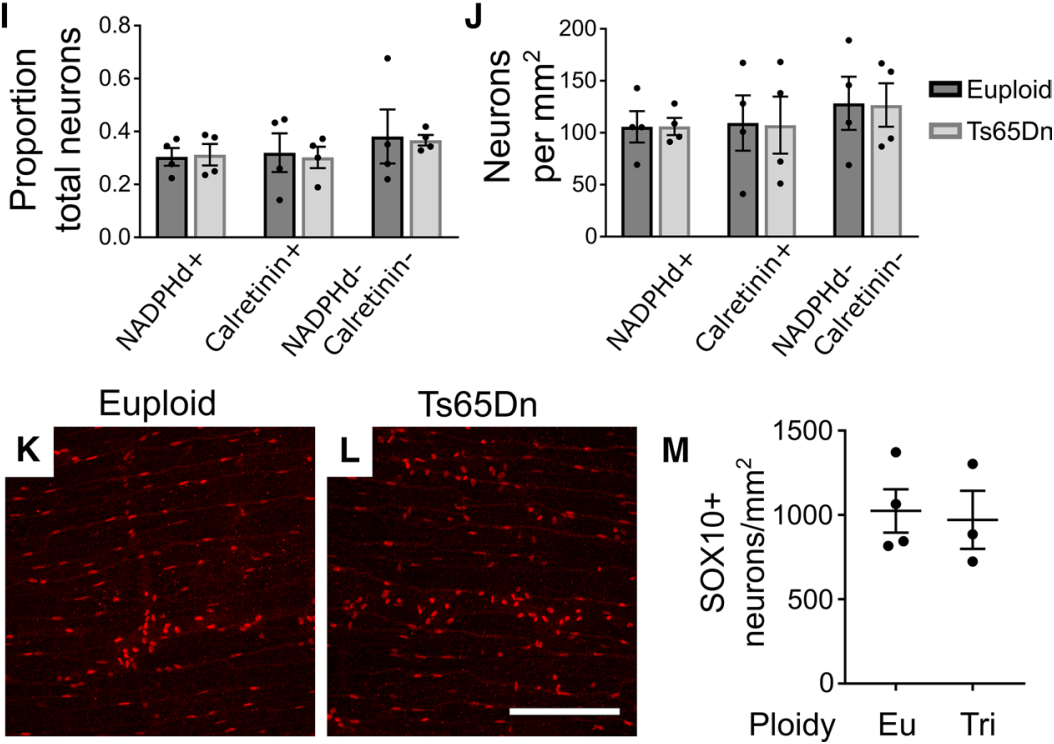

Figure 4. Density of NADPH diaphorase ${ }^{+}$neurons, calretinin $^{+}$neurons, and $\mathrm{SOX}^{+} 0^{+}$glia is normal in Ts65Dn adult small bowel. Ts65Dn adult trisomic myenteric plexus from small bowel was stained with antibodies against HuC/D ( $\mathbf{A}$ and $\mathbf{E}$ ) and calretinin (B and $\mathbf{F}$ ) and also stained using NADPH diaphorase histochemistry, which was pseudocolored blue to merge with fluorescent images (C and G). Merged images ( $\mathbf{D}$ and $\mathbf{H}$ ) show NADPHd ${ }^{+}$, calretinin ${ }^{+}$, and NADPHd ${ }^{-} /$calretinin $^{-}$neurons. (I) Ts65Dn mice had normal ratios of specific neuron subtypes to total neurons (NADPH: $P=0.881, t$ test, $n=4$ [euploid] and $n=4$

[Ts65Dn]; calretinin: $P=0.839, t$ test, $n=4$ [euploid] and $n$ $=4$ [Ts65Dn]; NADPHd ${ }^{-}$/calretinin ${ }^{-}: P=0.898, t$ test, $n=4$ [euploid] and $n=4$ [Ts65Dn]) and (J) absolute neuron density (NADPH: $P=0.986, t$ test, $n=4$ [euploid] and $n=4$ [Ts65Dn]; calretinin: $P=0.960, t$ test, $n=4$ [euploid] and $n=4$ [Ts65Dn]; NADPHd ${ }^{-} /$calretinin $^{-}: P=0.961, t$ test, $n=$ 4 [euploid] and $n=4$ [Ts65Dn]). ( $\mathbf{K}$ and $\mathbf{L}$ ) Adult myenteric plexus from euploid and Ts65Dn mid-small intestine was stained with anti-SOX10 antibody and imaged using confocal Z-stacks. Maximum intensity projections are shown. (M) Ts65Dn and euploid animals did not differ in numbers of myenteric $\mathrm{SOX}^{+} 0^{+}$glia $(P=0.980, t$ test, $n=4$ [euploid] and $n=3$ [Ts65Dn]). Scale bar: $100 \mu \mathrm{M}$.

critical region on Hsa21 thought to increase HSCR risk (Figure 9A). DSCAM is a netrin receptor, and netrin attracts ENS precursors to submucosal plexus during radial migration $(11,27,28)$. DYRK1A regulates neuronal precursor cell cycle, and DYRK1A overexpression impairs CNS neuron precursor proliferation (34). To determine if excess DSCAM or DYRK1A causes submucosal neuron hypoganglionosis, we normalized copy number in Ts65Dn mice by breeding Ts65Dn females to $D_{s c a m^{+-}}$or Dyrk1 ${ }^{+/-}$males. Offspring from Ts65Dn $\times \mathrm{Dscam}^{+/-}$crosses were on a mixed (C57BL/6J $\times$B6EiC3Sn) background, while offspring from Ts65Dn $\times$

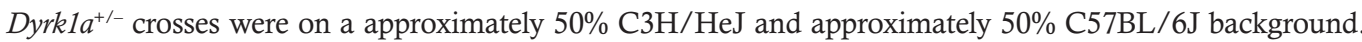
Quantitative HuC/D immunohistochemistry (Figure 9, B-K) showed submucosal neuron density remained low in trisomic Ts65Dn mice that had only 2 copies of either Dscam or Dyrk1a (i.e., not statistically different from mice with 3 copies of Dscam or Dyrk1a). This suggests normalizing Dscam and Dyrk1a copy number is insufficient to rescue submucosal plexus defects in Ts65Dn animals.

Unexpectedly, mice with only $1 \mathrm{Dscam}$ (Euploid, $\mathrm{Dscam}^{+-}$) copy had significantly increased myenteric plexus neuron density compared with WT euploid animals (Figure 10, A-E). Although this might occur if fewer ENCDC migrated from myenteric to submucosal regions in Euploid, Dscam ${ }^{+/-}$mice, submucosal neuron density was not reduced compared with that in Euploid, Dscam ${ }^{+/+}$mice (Figure 9J). Since numerous studies suggest that DSCAM may be a risk allele for HSCR, we also investigated rostrocaudal colonization of developing bowel in $\mathrm{Dscam}^{-/-}$mice but found normal extent of colonization at E12.5 (Figure 10, F-H). These data suggest that Dscam heterozygosity increases neuronal density in the myenteric plexus, but Dscam copy number alone has minimal, if any, effect on longitudinal or radial ENCDC migration in developing bowel.

\section{Discussion}

ENS structure and function in trisomy 21 - clues from mouse models. Surgical resection of distal aganglionic bowel has been the gold-standard treatment for HSCR for 70 years $(60,61)$, but $>30 \%$ of people with HSCR have problems after surgery $(13,20)$. Intriguingly, meta-analysis of 16,497 people with HSCR showed that children with DS and HSCR have considerably worse postoperative outcomes than children 

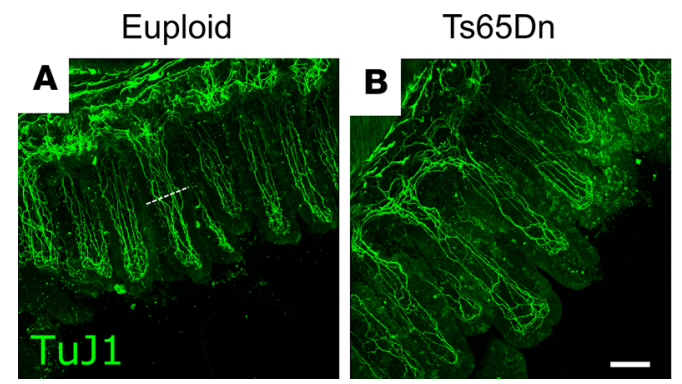

\section{C}

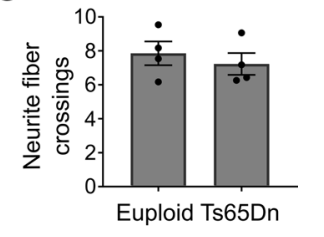

Figure 5. Neurite density within villi is normal in trisomic mice. (A and B) Representative Z-projections of Tuj1+ nerve fibers in mid-small bowel villi from euploid (A) and Ts65Dn (B) mice. (C) Quantification of villus neurite fiber crossings shows no difference between euploid and Ts65Dn mice ( $P=$ $0.5366, t$ test, $n=4$ [euploid] and $n=4[$ Ts65Dn]). The white dotted line in $\mathbf{A}$ represents an example location where intersecting fibers were counted. Scale bar: $100 \mu \mathrm{M}$.

with HSCR alone, including higher rates of enterocolitis and soiling (14). These long-standing observations are not mechanistically understood. One possibility is that trisomy 21 not only increases HSCR risk, but also causes other changes in ENS structure and function. Consistent with this hypothesis, even without HSCR, people with DS have a high incidence of unexplained severe chronic constipation (between 19\% and $56 \%)$ and chronic diarrhea $(19 \%)(2,3)$. We recognize DS increases risk of other gastrointestinal problems (e.g., duodenal stenosis and imperforate anus) $(62,63)$, but our data support the hypothesis that ENS defects in addition to HSCR may contribute to bowel symptoms in people with DS.

Using 2 established DS mouse models (Ts65Dn and Tc1), we demonstrated normal rates of bowel colonization by ENCDC during fetal development but reduced submucosal neuron density in adult mice. Ts65Dn mice also had reduced myenteric neuron density in distal colon, but myenteric neuron density was normal in more mildly affected Tc1 mice. Interestingly, neurite fiber projections into villi appear normal in Ts65Dn small bowel, suggesting increased neurite length or branching from each innervating neuron as fewer cells compete for available trophic factors. The difference between Ts65Dn and Tc1 phenotypes may be due to Hsa21 mosaicism in Tc1 mice (46), incompatibility between mouse and human transcription factors on Hsa21, or differences in gene expression between Ts65Dn and Tc1 mice. We focused mechanistic studies on Ts65Dn mice because they had more severe ENS defects.

We next asked if reduced neuron density reflected loss of specific neuron subpopulations but found reduced density of multiple neuron subtypes, suggesting the problem precedes neuron subtype specification. We did not detect altered proliferation or cell death to account for the reduced neuron numbers. We also did not find increased glia that might reflect preferential precursor differentiation into glia at the expense of neuronal differentiation. We hypothesize reduced submucosal neuron density occurs because of reduced ENCDC migration from outer bowel wall to the submucosal plexus but have not found a method to directly test this hypothesis.

In conjunction with anatomic defects, Ts65Dn mice had prolonged colonic bead expulsion times. Interestingly, individual stool pellet weights in the B6EiC3Sn strain were also reduced in Ts65Dn mice, but as we generated a mixed $\mathrm{B} 6 \mathrm{EiC} 3 \mathrm{Sn} \times \mathrm{C} 57 \mathrm{BL} / 6 \mathrm{~J}$ background that bred more efficiently, weight per stool pellet normalized, consistent with the observation that strain background affects other DS phenotypes $(64,65)$.

Although the detected bowel motility problems did not cause life-threatening disease, these studies show for the first time to our knowledge that 2 DS mouse models have reduced enteric neuron density and that Ts65Dn mice have colonic dysfunction. Our findings are intriguing, leading us to speculate that bowel problems in children with DS could reflect ENS abnormalities even in the absence of HSCR. Further research using human tissue will be needed to test this hypothesis. Given low HSCR frequencies in children with DS (i.e., 2.6\%), we were not surprised that Ts65Dn and Tc1 mice studied had enteric neurons throughout the bowel and that extent of bowel colonization was normal at E12.5. Because many children with DS and HSCR have reduced RET levels (e.g., RET hypomorphic T allele [rs2435357 SNP]) (15), we generated Ts65Dn, Ret $^{+/-}$mice, but these animals also had normal ENCDC bowel colonization at E12.5, a sensitive time for detecting delayed ENS precursor migration. Additional work could be done to determine if Ts65Dn or Tc1 trisomies increase penetrance of HSCR-like disease in mice with other predisposing mutations, but this may require analysis of hundreds of animals, given low HSCR penetrance in people with DS.

Trisomic Dscam or Dyrk1a alone does not explain submucosal plexus defects in Ts65Dn mice. Reduced submucosal neuron density in Ts65Dn animals is interesting because mechanisms controlling radial migration of ENCDC from myenteric to submucosal plexus layers are poorly understood. Data suggest sonic hedgehog $(\mathrm{SHH})$, GDNF, and netrin-1 all affect radial migration. SHH appears to repel ENCDC, since SHH is produced in gut epithelium and $\mathrm{SHH}$-deficient mice have ectopic enteric neurons too close to the epithelial lining. In contrast, 


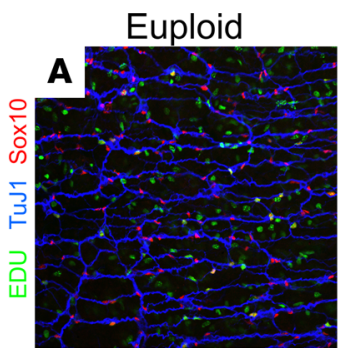

D

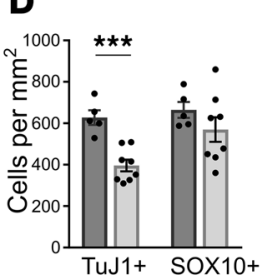

$\mathbf{E}$
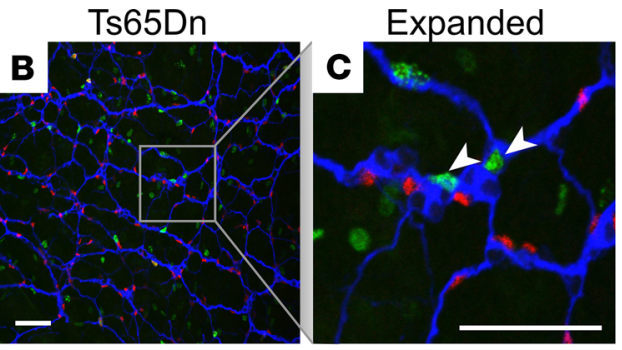

$\mathbf{F}$
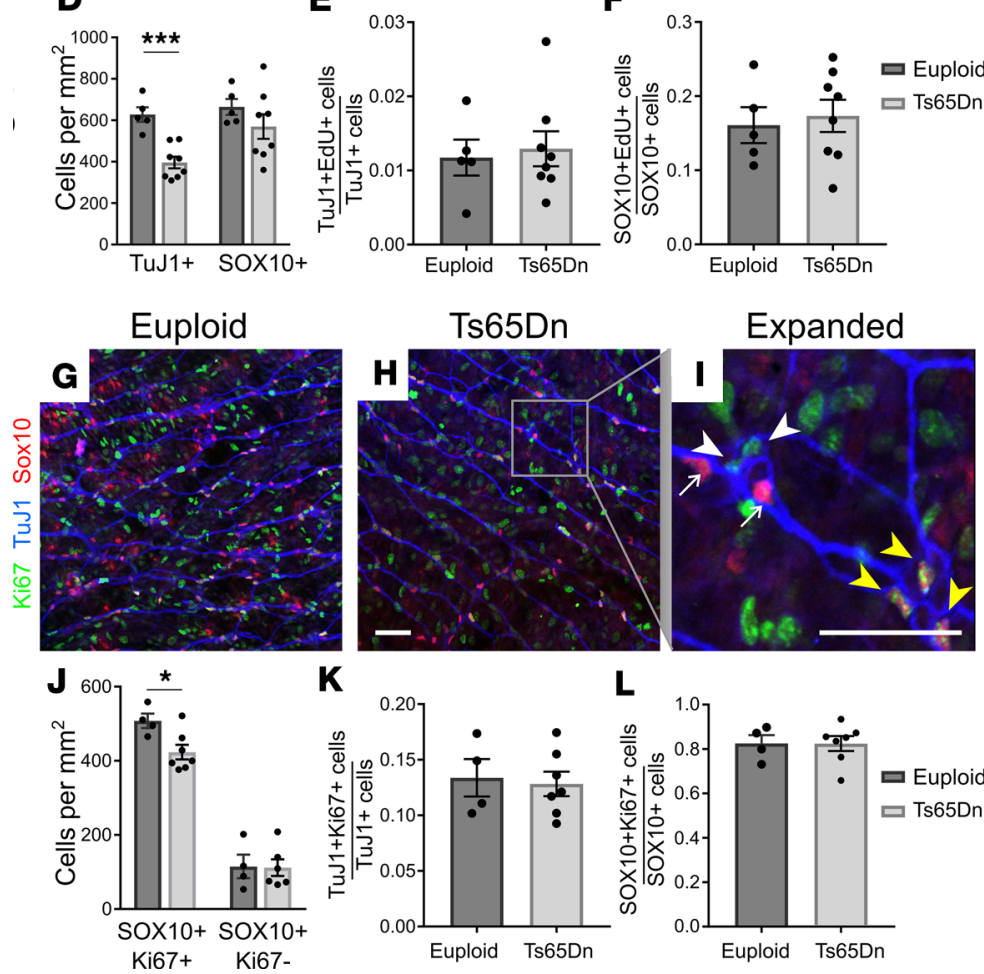

\section{$\mathbf{K}$

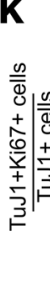

$\mathbf{L}$

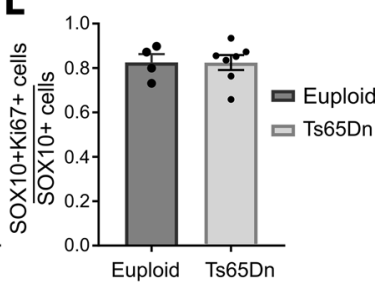

Figure 6. Neuronal and glial precursor proliferation were normal in Ts65Dn mice. (A, B, G, and H) Euploid and Ts65Dn P1 submucosal plexuses from small bowel were labeled with EdU ClickIT chemistry (green) plus antibodies against SOX10 (red) and Tul1 (blue) antibodies (A and B) or with antibodies to Ki67 (green), SOX10 (red), and Tuj1 (blue) (G and $\mathbf{H}$ ). In higher-magnification images (C and I), white arrowheads indicate $\mathbf{T u} \mathbf{1}^{+} \mathrm{EdU}^{+}$(C) or $\mathrm{Tu}) 1^{+} \mathrm{Ki} 67^{+}$(I) neuron precursors; yellow arrowheads indicate SOX-

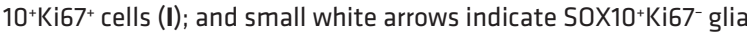
(I). (D) TuJ1+ cell density was significantly reduced in P1 Ts65Dn submucosal plexus ( $P<0.001, t$ test, $n=5$ [euploid] and $n=8$ [Ts65Dn]), while SOX10+ cell density was not significantly reduced in Ts65Dn animals ( $P=0.267, t$ test; $n=5$ [euploid] and $n=8$ [Ts65Dn]). (E and F) The proportion TuJ1+EdU+ precursors relative to total TuJ1 $1^{+}$neurons $(\mathbf{E})$, and the proportion $\mathrm{SOX} 10^{+} \mathrm{EdU}{ }^{+}$cells relative to total S0X10+ cells (F), was unchanged in P1 Ts65Dn submucosal plexus (TuJ1+EdU ${ }^{+}$proportion: $P=0.747, t$ test, $n=5$ [euploid] and $n=8$ [Ts65Dn]; S0X10+EdU+ proportion: $P=0.719$, $t$ test; $n=5$ [euploid] and $n=8$ [Ts65Dn]). (J) P1 Ts65Dn mice had

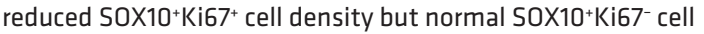
density (SOX10+Ki67 : $P=0.0214, t$ test, $n=4$ [euploid] and $n=$ 7 [Ts65Dn]; SOX10'Ki67-: $P=0.748, t$ test, $n=4$ [euploid], $n=4$ [Ts65Dn]). (K and $\mathbf{L}$ ) The proportion Tuj $1^{1+K i 67^{+}}$precursors relative to total TuJ $1^{+}$neurons $(\mathbf{K})$, and the proportion SOX10+Ki67+ cells relative to total $\mathrm{SOX} 10^{+}$cells $(\mathrm{L})$, was unchanged in $\mathrm{P} 1 \mathrm{Ts} 65 \mathrm{Dn}$ submucosal plexus (TuJ1 $1^{+} \mathrm{Ki} 67^{+}$proportion: $P=0.782$, $t$ test, $n=4$ [euploid] and $n=7$ [Ts65Dn]; SOX10+Ki67+ proportion: $P=0.992$, $t$ test; $n=4$ [euploid] and $n=7$ [Ts65Dn]). Scale bars: $50 \mu \mathrm{m}$. All images are confocal Z-stacks. ${ }^{*} P<0.05,{ }^{* *} P<0.001$.

GDNF signaling via RET and GDNF receptor $\alpha 1$ (GFRA1) promotes ENCDC migration toward submucosal plexus, as suggested by the observation that conditional deletion of Gfral or Ret at E13.5 dramatically reduces submucosal neuron density. ENCDC death does not account for this phenotype (12). Instead, GDNF appears to attract ENCDC, and GDNF expression shifts from outer gut mesenchyme to the submucosal side of the circular muscle layer late in embryonic development. This makes it plausible that GDNF could attract ENCDC to submucosal plexus (12). Netrin-1 also attracts ENCDC to submucosal plexus by binding deleted in colon cancer (DCC). Mice lacking DCC have no submucosal ganglia at P0 (11). While these data implicate SHH, GDNF, and netrin-1 signaling in radial migration, it remains unclear how trisomy 21 might influence submucosal neuron number. One hypothesis is that overexpression of a gene in the trisomic region of Ts65Dn or Tc1 mice alters GDNF, netrin-1, or SHH signaling to reduce submucosal neuron number, but these signaling pathways are complicated and there are many ways that they could be altered. Intriguingly, trisomy has been linked to SHH signaling deficits in neuronal precursors in Ts65Dn mice (66-68), but increased $\mathrm{SHH}$ signaling would presumably be needed to reduce submucosal neuron number.

To test the role of specific genes in the ENS phenotype of Ts65Dn mice, we focused initially on Dscam because DSCAM is a receptor for netrin-1, and prior studies suggested that DSCAM overexpression may increase HSCR risk $(23-26,69)$. In the central nervous system, DSCAM mediates spinal commissural axon turning in response to netrin-1 (27) and DSCAM patterns the retina via self-repulsion. DSCAM can increase or decrease adhesion between cells depending on context $(70,71)$, making it likely that DSCAM abundance would affect ENS development, as DSCAM is expressed in ENCDC at ages critical for ENS precursor migration and differentiation (25). These findings led us to hypothesize that 3 copies of Dscam in Ts65Dn mice might reduce submucosal neuron number. Surprisingly, normalizing Dscam copy number by 


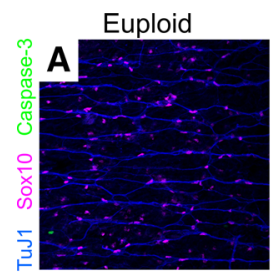

Euploid

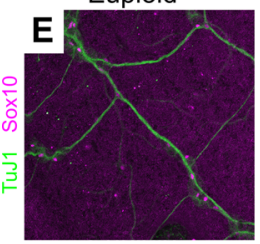

Ts65Dn

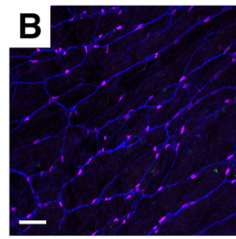

Ts65Dn

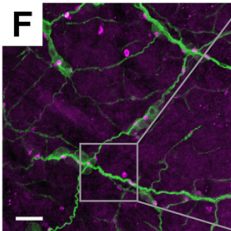

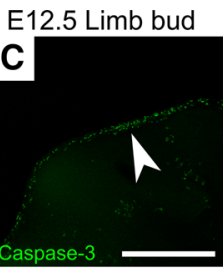

Expanded

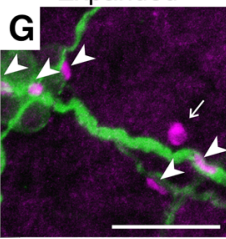

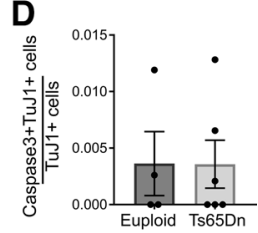

H

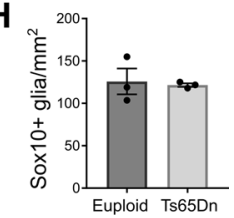

Figure 7. Apoptosis and glial number were normal in Ts65Dn submucosal plexus. (A and B) P1 bowel stained with antibody against cleaved caspase-3 (green) had few immunoreactive cells. (C) E12.5 mouse proximal limb was used as a positive control for cleaved caspase-3 antibody staining to ensure apoptotic cells were readily detected by the antibody. White arrowhead indicates densest region of apoptotic cells. (D) Quantitative analysis of cleaved caspase-3 data $(P=$ 1.0, MWRST, $n=4$ [euploid] and $n=6$ [Ts65Dn]). (E and F) Adult small intestine showing SOX10+ mature glia (magenta) in proximity to TuJ1+ (green) neuron processes. In the expanded image (G), arrowheads indicate $50 \times 10^{+}$glia, and arrows indicate autofluorescent blood cells, which were not counted. (H) Quantitative analysis of SOX10+ mature glia in adult submucosal plexus ( $P=0.59, t$ test, $n=3$ [euploid] and $n=3$ [Ts65Dn]). Scale bars: $50 \mu \mathrm{m}$ (A, B, and E-G); $500 \mu \mathrm{m}$ (C). All images are confocal Z-stacks.

generating Ts65Dn, Dscam ${ }^{+/+-}$mice did not prevent submucosal plexus hypoganglionosis. Furthermore, Dscam heterozygosity did not alter submucosal neuron number, and loss of Dscam did not alter bowel colonization by ENCDC in euploid mice. Intriguingly, Euploid, $\mathrm{Dscam}^{+/-}$adult mice had elevated myenteric neuron density compared with WT mice, but the significance of this mild neuron density increase is uncertain. Increased myenteric neuron number might be linked to the observation that loss of DSCAM increases neuron proliferation in the medulla (72), but mechanisms underlying this observation are not known. Collectively, our findings raise questions about whether DSCAM has important roles in ENS precursor migration as previously hypothesized (23).

We also tested the hypothesis that excess DYRK1A causes submucosal hypoganglionosis in Ts65Dn mice. DYRK1A is part of the HSCR-associated critical region on Hsa21 and encodes a tyrosine kinase with diverse functions. In mouse neocortex, DYRK1A induces premature neuronal differentiation through effects on cyclin D1 (73). If DYRK1A excess also induced premature differentiation of ENCDC, hypoganglionosis would be expected. However, restoring normal Dyrkla copy number did not prevent submucosal plexus hypoganglionosis in otherwise trisomic Ts65Dn mice, and Dyrkla haploinsufficiency did not alter submucosal neuron density in euploid mice.

Collectively, these data show that two mouse DS models, one partial trisomy and one transchromosomal, have submucosal plexus hypoganglionosis, but critical genes causing this problem remain uncertain. Identifying key genes is challenging because Ts65Dn and Tc1 mice share approximately 68 triplicated genes. Several additional candidates found in 3 copies in Ts65Dn and Tc1 mice include Bace2, Chaf1b, Fam3b, and Pcp4 (24). Triplication of these genes was reported in 3 children with HSCR and partial trisomy 21 (67). BACE2 is especially interesting because variants are linked to HSCR, knockdown, or inhibition of BACE2 rescued migration defects in human embryonic stem cell-derived ENS precursors (74), and some BACE2 variants prevent enteric neuron apoptosis (75). Other encoded proteins influence migration of non-ENCDC cell types but do not have known ENS roles. Submucosal plexus hypoganglionosis in Ts65Dn and Tc1 mice might also be due to cooperative effects of multiple simultaneously overexpressed genes. For example, in Drosophila, COL6A2, and DSCAM exert synergistic effects on cardiac development. Overexpression of both COL6A2 and DSCAM causes atrial septal defects that do not occur with overexpression of the individual genes (76). This complexity underscores the difficulties in defining mechanisms in polygenic diseases, such as DS and HSCR.

HSCR, hypoganglionosis, and DS. It is unclear why we did not observe aganglionic bowel in Ts65Dn or Tc1 mouse models. Perhaps we would have found mice with short-segment aganglionosis if we had evaluated hundreds of animals, since humans with DS only have $2.6 \%$ HSCR occurrence rates (130-fold increased risk). Nonetheless, our data clearly show that Ts65Dn mice have reduced distal bowel ENS densi- 


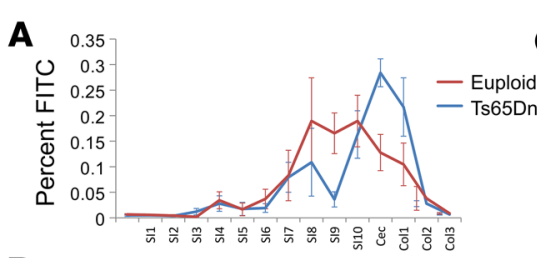

$\mathbf{B}$

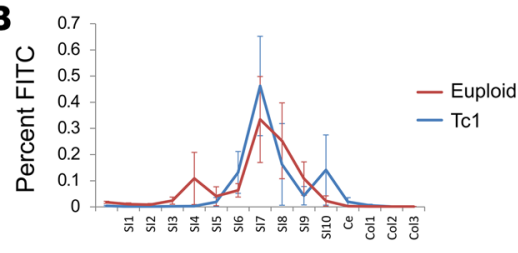

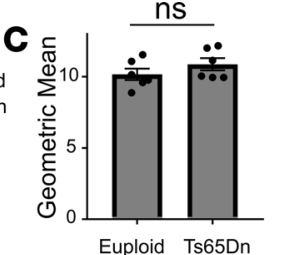

D

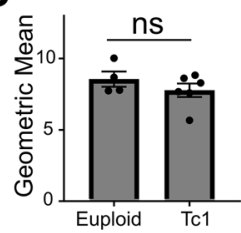

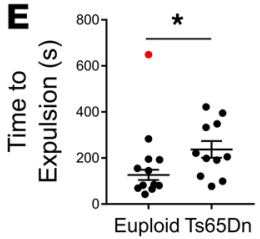

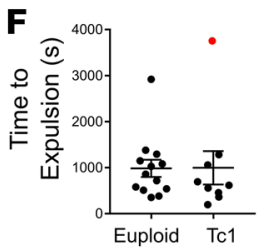

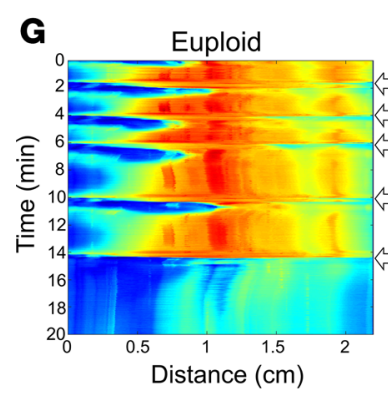

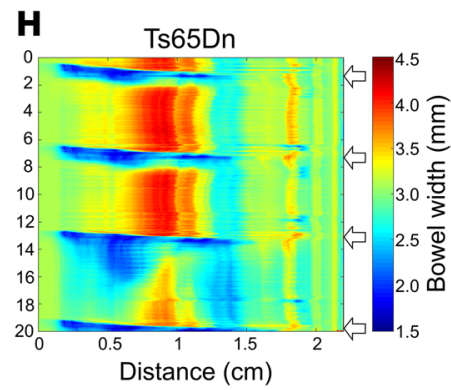

I
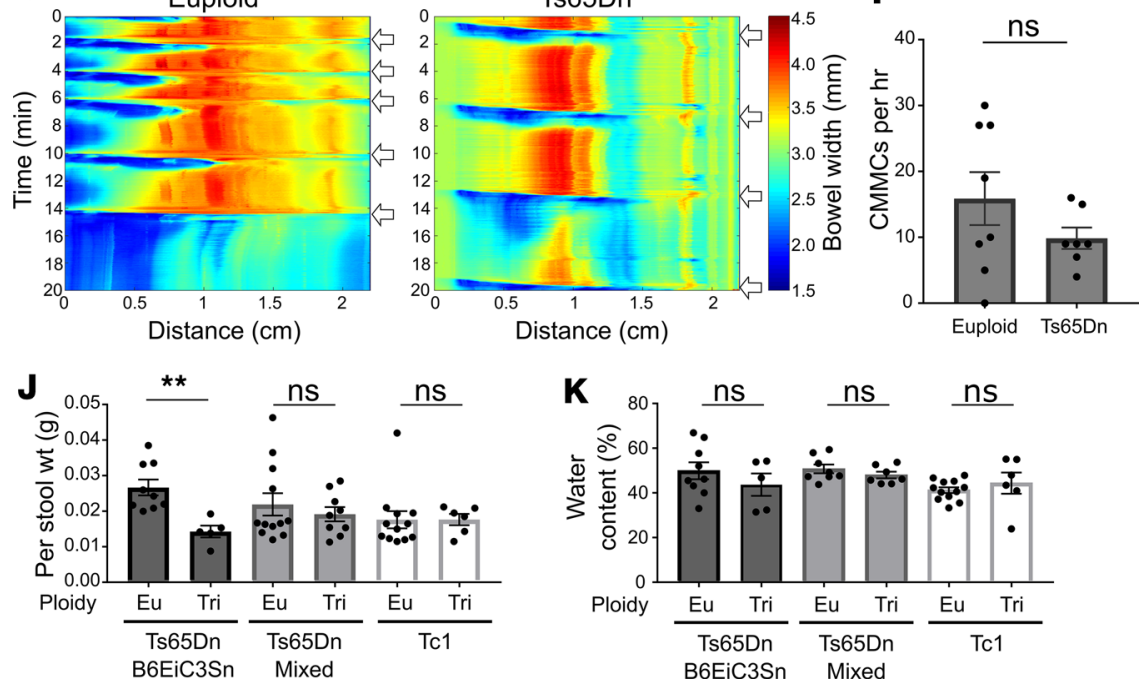

Figure 8. Ts65Dn mice have altered bowel motility and stooling patterns. (A-D) Proximal bowel transit was measured by quantifying FITC-dextran in bowel segments after gavage. There was no difference between each segment's FITC content (A and $\mathbf{B}$; $t$ tests with Holm-Sidak multiple comparisons correction) or between geometric means of trisomic and euploid mice (Ts65Dn: C, $P=0.255, t$ test, $n=6$ [euploid] and 6 [Ts65Dn]; Tc1: $\mathbf{D}, P=0.311, t$ test, $n=6$ [euploid] and 4 [Ts65Dn]). (E and F) Colon transit, measured by inserting a glass bead into distal colon and timing expulsion, was no different with all data points included (E, $P=0.0595$, MWRST; $n=12$ [euploid] and $n=11$ [Ts65Dn]) but was significantly increased in Ts65Dn mice when one outlier (red; ROUT and Grubb's Outlier tests) was removed (E, $P=0.0117 ; t$ test; $n=11$ [euploid] and $n=11$ [Ts65Dn]). No difference in colonic bead expulsion time occurred in Tc1 mice (F, $P=0.26$; MWRST; $n=13$ [euploid] and $n=9$ [Tc1]), even when one outlier (ROUT analysis, red) was removed $(P=0.232 ;$ MWRST). (G and $\mathbf{H})$ Representative kymographs plotting bowel width as a function of time and bowel distance for euploid (G) and Ts65Dn (H) colon maintained at 2-cm pressure in an oxygenated organ bath. (I) CMMC (white arrows) frequency in Ts65Dn mice was not significantly different from euploid littermates $(P=0.30$, MWRST, $n=8$ [euploid] and $n=7$ [Ts65Dn]). (J) Per stool weight was significantly larger in Ts65Dn mice on a B6EiC3Sn background (G, $P=0.003, t$ test, $n$ $=9$ [euploid] and $n=5$ [Ts65Dn]) but normal for Ts65Dn mice on a mixed (B6EiC3Sn $\times$ C57BL/6J) background $(P=0.749$, MWRST, $n=12$ [euploid] and $n=9$ [Ts65Dn]) or Tc1 mice $(P=0.482$, MWRST, $n=12$ [euploid] and $n=6$ [Ts65Dn]). (K) Stool water content was normal for all strains tested (B6EiC3Sn: $P=0.346, t$ test, $n=9$ [euploid] and $n=5$ [Ts65Dn] mixed background: $P=0.297, t$ test, $n=8$ [euploid] and $n=7$ [Ts65Dn]; Tc1: $P=0.526$, MWRST, $n=12$ [euploid] and $n=6$ [Ts65Dn]). ${ }^{*} P<0.05,{ }^{*} P<0.01$.

ty and reduced submucosal neuron density. Additional genetic or nongenetic risks may be needed to cause aganglionosis. Interestingly, trisomy 16 mice do not survive past birth, and a subset have complete colonic aganglionosis over short regions $(77,78)$. Trisomy 16 mice have 3 copies of some genes homologous to Hsa21 but also have extra copies of genes homologous to other human chromosome regions, so they only partially mimic human DS. It is possible additional HSCR risk alleles relevant to human DS are present in trisomy 16 compared with Tc1 or Ts65Dn mice and increased expression of more than one gene affects distal bowel ENS morphogenesis. An alternative is that mouse strain background influences severity of 


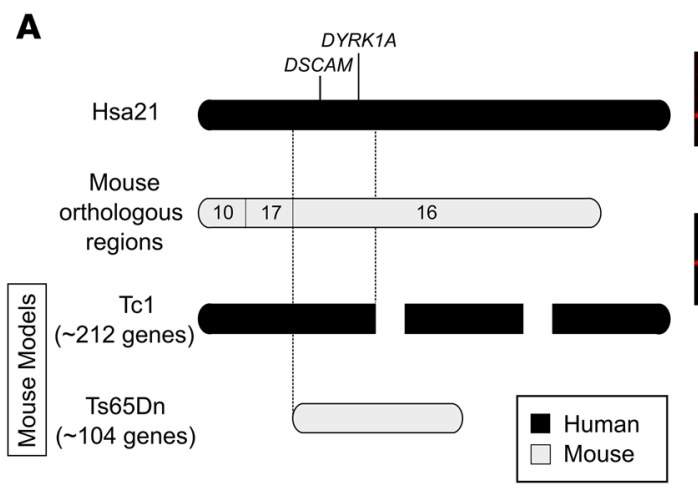

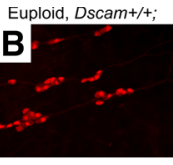

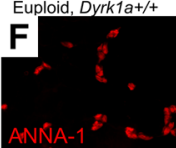

$\mathbf{J}$

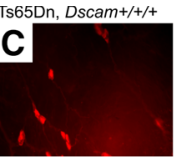
G

Ts65Dn, Dscam

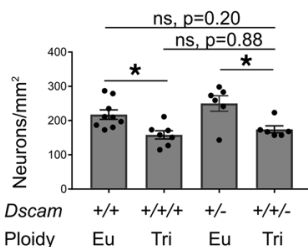

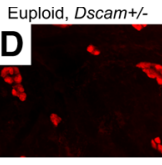

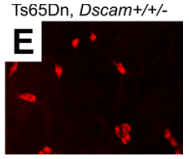

Euploid, Dyrk1a+/H I

K

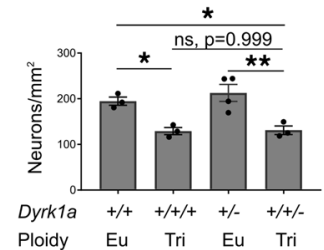

Figure 9. Normalizing Dscam or Dyrk1a gene copy number in Ts65Dn mice does not correct the submucosal plexus hypoganglionosis. (A) Map of Ts65Dn and Tc1 trisomic regions. (B-E) Submucosal plexus of adult Euploid, Dscam ${ }^{+/+} ;$Ts65Dn, Dscam st/++/; Euploid, Dscam $^{+/-}$; and Ts65Dn, Dscam ${ }^{+/+/}$; and

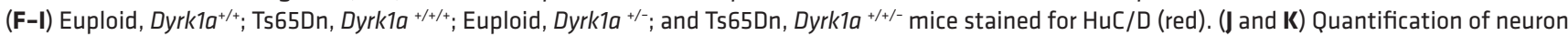
density from images, such as B-I, indicates normalizing copy number for Dscam and Dyrk1a did not prevent distal colon hypoganglionosis $(P=0.201$ Euploid, Dscam ${ }^{+/+}$versus Ts65Dn, Dscam ${ }^{+/+-}$and $P=0.884 \mathrm{Ts65Dn}, D_{\text {scam }}^{+/+} /{ }^{+}$versus Ts65Dn, Dscam ${ }^{+/+-}$, ANOVA with post-hoc Tukey test; $n=9$ [Euploid, Dscam $^{+/+}$], $n=7$ [Ts65Dn, Dscam ${ }^{+/++}$], $n=6$ [Euploid, Dscam ${ }^{+/}$], and $n=6$ [Ts65Dn, Dscam ${ }^{+/+/}$]) or DYRK1A ( $P=0.048$ Euploid, Dyrk1a ${ }^{+/+}$versus Ts65Dn, Dyr-

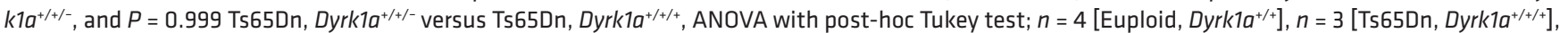
$n=3$ [Euploid, Dyrk1a+/-], and $n=3$ [Ts65Dn, Dyrk1a $\left.a^{++/-}\right]$). Scale bar: $100 \mu \mathrm{m} .{ }^{*} P<0.05,{ }^{* *} P<0.01$.

ENS defects in these models (as is well known for other mouse HSCR models, ref. 79). If this is true, shared trisomic genes could underlie HSCR risk, causing hypoganglionosis in Tc1 and Ts65Dn mice but more severe reductions in neuron number (i.e., aganglionosis) in trisomy 16 animals. Adding complexity, mouse and human chromosomes are not completely syntenic. For example, postulated HSCR risk genes COL6A1 and COL6A2 encode collagen on Hsa21 and excess collagen slows ENCDC migration (49), but mouse homologs are on Mmu10 (49) and are not triplicated in Ts65Dn or trisomy 16 mice (80). These issues leave many avenues for future investigation to define why children with DS have increased HSCR risk and more frequent and severe bowel problems, even after HSCR surgery.

Summary. Our work defines a model in which additional DS candidate genes can be tested for their effect on ENS development using heterozygous inactivating mutations in combination with Ts65Dn trisomy to determine if increased copy number causes distal bowel hypoganglionosis. Our studies also provide a potentially new hypothesis to explain why some people with DS experience severe functional bowel defects without bowel aganglionosis. Future studies should explore ENS structure and function in human DS, an area in need of additional research. Unfortunately, normal values for submucosal neuron density are not established in humans and reported myenteric neuron density values vary $>20$-fold (81). Furthermore, effects of age and bowel region on neuron density are not known, so defining how DS affects ENS structure in humans will require extensive systematic effort, mapping colon location, employing quantitative 3-dimensional imaging, and comparing bowel resected during HSCR surgery in children with and without DS.

\section{Methods}

Animals. Dscam mice on a C57BL/6J background were from Robert Burgess at The Jackson Laboratory (stock 008000). The B6EiC3Sn $a / A$-Ts $\left(17^{16}\right) 65 \mathrm{Dn} / \mathrm{J}$ (referred to as Ts65Dn) mice were from The Jackson Laboratory (stock 001924). Male Ts65Dn mice are subfertile, and Ts65Dn females breed poorly. Unless otherwise stated, all Ts65Dn mice were maintained on the same recombinant inbred background as at The Jackson Laboratory (B6EiC3Sn). Trisomic mice with 2 copies of Dscam were generated by breeding $\mathrm{Dscam}^{+/-}$males (C57BL/6J) to trisomic Ts65Dn females (B6EiC3Sn). These mice were maintained by strictly breeding brothers and sisters for 3-4 generations and analyzing offspring from each generation. Some Euploid, $\mathrm{Dscam}^{+/+}$and Ts65Dn, Dscam ${ }^{+/+/+}$mice on this mixed B6EiC3Sn $\times$ C57BL/6J background were used in functional studies. Dyrk1a mice were originally generated by Mariona Arbones (Institut de Biologia Molecular de Barcelona-CSIC, Barcelona, Spain)

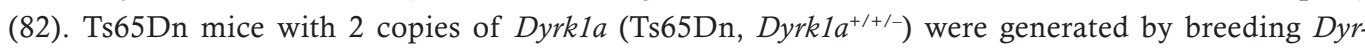



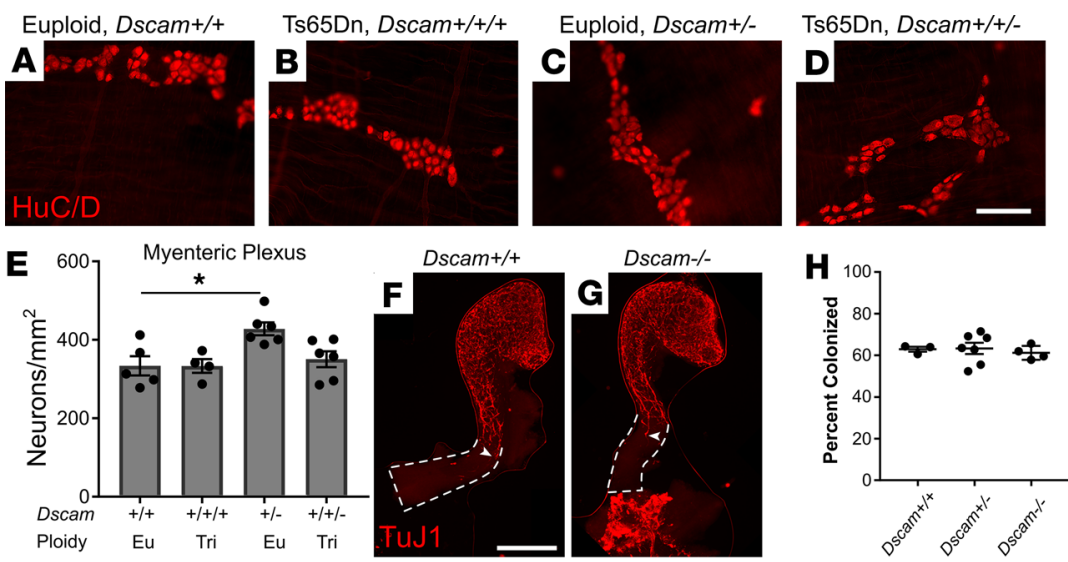

Figure 10. Adult Dscam heterozygous mice have increased myenteric plexus neuron density but normal bowe colonization rate by ENCDC. (A-D) HuC/D staining of adult small bowel myenteric plexus in adult Euploid, Dscam $/++$; Ts65Dn, Dscam ${ }^{+/+} /+$; Euploid, Dscam ${ }^{+/-}$; and Ts65Dn, Dscam ${ }^{+/+-}$mice. Scale bar: $100 \mu \mathrm{m}$. (E) Quantification of neurons reveals increased myenteric plexus density in mice with 1 copy of $\operatorname{Dscam}\left(P=0.0169\right.$ Euploid, Dscam ${ }^{+/+}$versus Euploid Dscam ${ }^{+/}$, ANOVA with post-hoc Tukey test; $n=5$ [Euploid, Dscam ${ }^{+/+}$], $n=4$ [Ts65Dn, Dscam ${ }^{+/+} /{ }^{+}$], $n=6$ [Euploid, Dscam ${ }^{+/-}$], and $n=6$ [Ts65Dn, Dscam ${ }^{+/+-}$). (F and G) Tuj1-stained large bowel of E12.5 Dscam ${ }^{+/+}$and Dscam ${ }^{-/-}$mice. Scale bar: $500 \mu \mathrm{m}$. (H) Quantification of proportion of colonized colon in E12.5 mice with 2, 1, or 0 copies of DSCAM $(P=$ 0.838, ANOVA, $n=3\left[\right.$ Dscam $\left.^{+/+}\right], n=7\left[\right.$ Dscam $\left.^{+/}\right], n=4\left[\right.$ Dscam $\left.\left.^{-/}\right]\right) .{ }^{*} P<0.05$.

$k 1 a^{+/-}$males to Ts65Dn females. These mice were maintained on a approximately $50 \%$ C57BL/6J and approximately 50\% C3H/HeJ background as described previously (83). The B6129S-Tc(HSA21)1Ty$\mathrm{bEmcf} / \mathrm{J}$ (referred to as Tc1) mice were from The Jackson Laboratory (stock 010801) and maintained on a C57BL/ $6 \times 129 \mathrm{~S} 8 / \mathrm{SvEv}$ background by breeding Tc1 females to euploid males. Ret ${ }^{+/-}$mice on a C57BL/6J background have been previously described (84). Ts65Dn, Ret $^{+/+/}$mice were generated by breeding Ts65Dn females (B6EiC3Sn) to Ret $^{+/-}$males (C57BL/6J).

Adult myenteric and submucosal plexus whole mount bowel preparations. Whole gut from adult mice (80-120 days old) was processed as described previously (85). Briefly, bowel was rinsed in cold PBS. Entire colon and $5-\mathrm{cm}$ mid-small intestine were opened along the mesenteric border and pinned flat onto Sylgard 184 Silicone Elastomer (Dow Corning). Flattened gut was fixed (4\% paraformaldehyde, 30 minutes, room temperature), and muscle layers were separated from submucosa by careful dissection. Samples were cut into $1-\mathrm{cm}$ pieces and stored in 50\% glycerol $/ 50 \% \mathrm{PBS}\left(-20^{\circ} \mathrm{C}\right)$ until staining. For villus analysis, muscle layers were not separated from submucosa. Thin $(\sim 1 \mathrm{~mm})$ cross-sectional pieces of bowel containing multiple villi were cut with a scissors prior to staining. Mid-small intestine, mid-colon, and distal colon were used for all described analysis unless noted.

Submucosal plexus analysis at P1. P1 mice were injected intraperitoneally with EdU (12.5 $\mu \mathrm{g} / \mathrm{g}$; Click-iT EdU Alexa Fluor 488 Imaging Kit, Thermo Fisher Scientific, C10337) and maintained on a far infrared warming pad (Kent Scientific; DCT-20) at $30^{\circ} \mathrm{C}$. After 4 hours, mid-small bowel was dissected, pinned flat, and fixed (4\% paraformaldehyde). Muscle was dissected off submucosa and tissue was stored in $50 \%$ glycerol $/ 50 \%$ PBS $\left(-20^{\circ} \mathrm{C}\right)$ until staining.

Immunohistochemistry and enzymatic staining. Adult bowel stored in glycerol was washed twice in PBS and blocked (room temperature for 1 hour or $4^{\circ} \mathrm{C}$ overnight) in Tris-buffered saline/ $0.1 \%$ Triton X-100 (TBST) or PBS $/ 0.1 \%$ Triton X-100 (PBST) containing 5\% Normal Donkey Serum (Jackson ImmunoResearch Laboratory). Primary antibody incubations were at $4^{\circ} \mathrm{C}$ overnight. Antibody details are in Supplemental Table 1. Tissues were washed 3 times in TBST or PBST and incubated in secondary antibody (1 hour, room temperature). NADPH-diaphorase staining was performed as described previously (86). Briefly, Nitro Blue Tetrazolium (Roche) and NADPH (MilliporeSigma) were dissolved in PBS with $0.2 \%$ Triton X-100. Samples were incubated for $15-30$ minutes at $37^{\circ} \mathrm{C}$ to develop blue color. After PBS washes, samples were stained with antibodies as described above. Samples were mounted on glass slides in $50 \%$ glycerol/50\% PBS. For P1 analyses, all above steps were followed except submucosa was pinned flat on Sylgard-treated 48-well plates during staining to maximize antibody exposure. EDU labeling was performed using the Click-iT EdU Alexa Fluor 488 Imaging Kit (Thermo Fisher Scientific, C10337). 
Quantitative analysis of whole gut samples. For E12.5 mice, we measured total colon length from tip of cecum to end of colon and also position of most distal TuJ $1^{+}$nerve fiber as previously described (69). Neuron density, glial cell density, and neuronal subtype analyses were performed by counting all stained cells in 10 randomly selected $\times 20$ fields from each sample. All counting was done by observers blinded to genotype.

Mid-gut slice explant culture. E12.5 mouse small bowel was cut into 300-500 $\mu \mathrm{M}$ slices, plated on fibronectin-coated ( $250 \mu \mathrm{g} / \mathrm{ml}$; Life Technologies) plastic or glass Lab-Tek Permanox chamber slides (Thermo Fisher) and incubated in OptiMem (Life Technologies) supplemented with 2 mM L-glutamine (Life Technologies), $100 \mathrm{IU} / \mathrm{ml}$ penicillin, and $100 \mu \mathrm{g} / \mathrm{ml}$ streptomycin (Life Technologies). GDNF (100 ng/ml final concentration) was added to cultures 4 hours after plating. Sixteen hours after GDNF addition, cultures were fixed (4\% paraformaldehyde, room temperature, 20 minutes) and immunostained with RET antibody (Neuromics), phalloidin (to highlight F-actin) and 4',6-diamidino-2-phenylindole, dihydrochloride (DAPI). The distance between farthest-migrating ENCDC and gut slice edges was measured for 8 slices per chamber well.

Small bowel transit assay. Adult mice fasted overnight were gavage-fed $100 \mu 1$ FITC-Dextran (10 mg/ $\mathrm{ml}$, molecular weight 70,000; MilliporeSigma, 46945) dissolved in 2\% methylcellulose (MilliporeSigma, 274429) in water. After 1 hour (Tc1) or 2 hours (Ts65Dn), bowel was removed and divided into 10 segments for small bowel, 2 segments for cecum, and 3 segments for colon. Each bowel segment was opened along the mesentery, placed in $400 \mu \mathrm{PBS}$, vortexed for 15 seconds, and spun 10 minutes (4000 RCF) to pellet tissue and debris. $100 \mu 1$ supernatant was analyzed using a 96-well plate reader (Turner Biosystems Modulus II Microplate Multimode Reader). A weighted geometric mean was calculated as (segment number $\times$ FITC fluorescence)/total FITC fluorescence, as described previously (87).

Microscopy. Images were acquired using Zeiss Axio Imager.A2, Axio Observer.A1, or LSM 710 microscopes and Zeiss Zen software. ImageJ (NIH) was used for image processing, which was limited to stitching multiple fields, rotating, cropping, and uniform color adjustments. Confocal images show single optical projections or maximum intensity projections.

Colonic bead expulsion assay. Adult mice were anesthetized with isoflurane for 1.5 minutes. A glass bead (3 mm, MilliporeSigma, Z143928) lubricated with sunflower seed oil (MilliporeSigma, S5007) was inserted $2 \mathrm{~cm}$ into the colon using a custom-made 3-mm rounded glass rod. Mice were placed in empty cages, and time to bead expulsion was recorded. Assay was repeated 3 times per mouse with $>48$ hours between procedures. Tc1 mice and controls were food deprived overnight prior to testing, but Ts65Dn mice and controls were not food deprived before testing.

Bowel motility in vitro. Colons from adult Ts65Dn mice and euploid littermates were rapidly and immediately placed in warmed $\left(37^{\circ} \mathrm{C}\right)$, oxygenated $\left(95 \% \mathrm{O}_{2}\right.$ and $\left.5 \% \mathrm{CO}_{2}\right)$ physiological saline (Krebs-Ringers solution; $118 \mathrm{mM} \mathrm{NaCl}, 4.6 \mathrm{mM} \mathrm{KCl}, 2.5 \mathrm{mM} \mathrm{CaCl}_{2}, 1.2 \mathrm{mM} \mathrm{MgSO}_{4}, 1 \mathrm{mM} \mathrm{NaH}_{2} \mathrm{PO}_{4}, 25 \mathrm{mM} \mathrm{NaHCO}_{3}$, $11 \mathrm{mM}$ D-glucose, $\mathrm{pH}$ 7.4). Intestinal contents were emptied by gently flushing bowel with physiological saline using a needle attached to a $20-\mathrm{ml}$ syringe. Distal-most centimeter of bowel was removed and fixed (4\% paraformaldehyde) for immunohistochemistry. Remaining colon was maintained in a continually perfused physiological saline organ bath (Hugo Sachs Elektronik Harvard Apparatus, D-79232) with a flow rate of $9 \mathrm{ml} / \mathrm{min}$. The colon was cannulated and intraluminal pressure was maintained using a liquid reservoir connected to the proximal colon raised to $2 \mathrm{~cm}$ above the fluid level in the organ bath. The outflow tube from the colon ended at $1 \mathrm{~cm}$ above the fluid level in the organ bath to induce continuous flow of Krebs-Ringer solution through the bowel. Cannulation in this manner reliably elicits CMMCs in adult mouse colon. After a 15-minute equilibration, video was recorded for 1 hour.

Video imaging. Videos were captured using an E-PM1 Olympus digital video camera mounted on a dissecting microscope (15 frames per second, 1,920 × 1,080 pixel resolution). Gut was well illuminated to accentuate contrast with the darker background. Videos were converted from MTS to WMV format using Windows Movie Maker. Spatiotemporal maps were generated using MATLAB (MathWorks) code generated in-house. The MATLAB code is freely available (https://github.com/christinawright100/BowelSegmentation/commit/095850905504f6ac29c7311f56fd9bf089ad4574, commit ID 958509). Briefly, a video frame was thresholded to distinguish gut from background. This thresholded image was used to measure bowel width at each point along the bowel length, generating a 1-dimensional array of widths. This process was repeated for relevant video frames (relevance was determined by desired sampling frequency) to generate a 2-dimensional spatiotemporal map. CMMCs (defined as contractions that extend at least half the length of the spatiotemporal map) were quantified by a trained investigator blinded to condition. 
Stool collection. Animals were placed in individual bedding-free cages with free access to food and water (88). One hour later, fecal pellets were collected, weighed to determine "wet" weight, and placed on a $100^{\circ} \mathrm{C}$ heat block in open tubes overnight to dry. Pellets were then weighed to determine "dry" weight and stool water content was computed as (wet weight - dry weight)/wet weight.

Statistics. SigmaPlot 11.0 (Systat Software) and Prism 7.03 (GraphPad Software) were used for statistical analyses. When comparing 2 groups, a 2-tailed Student's t-test was used unless assumptions were not met, in which case a MWRST was used. Multigroup analyses were performed using 1-way ANOVA with post hoc multiple-comparisons tests (Tukey). Data represent mean \pm SEM. A cutoff of $P<0.05$ was considered significant. All experiments used at least 3 biological replicates. All quantifications were performed by investigators blinded to condition.

Study approval. All animal experiments were approved by The Children's Hospital of Philadelphia or Indiana University-Purdue University Indianapolis Institutional Animal Care and Use Committees.

\section{Author contributions}

EMS, CMW, and ROH designed experiments, analyzed results, and wrote the manuscript. EMS, CMW, and AJ performed experiments. RJR and JML bred Ts65Dn, Dyrk1A mice, harvested their bowels, and provided thoughtful advice about study design and data interpretation. All authors edited the manuscript.

\section{Acknowledgments}

The authors thank Beth Maguire for mouse colony management assistance. We are grateful to Robert Burgess for providing Dscam mice and verifying strain background, to Mariona Arbonés for sharing Dyrk1a mice, and to Vanda Lennon for human ANNA-1 serum. We also thank Benjamin Wilkins and Amanda Lemke for insightful comments and assistance during manuscript preparation. This work was supported by the Irma and Norman Braman Endowment (to ROH), the Suzi and Scott Lustgarten Center Endowment (to ROH), the Children's Hospital of Philadelphia Research Institute (to ROH), the Children's Discovery Institute of Washington University and St. Louis Children's Hospital (grant MD-II2013-269) (to ROH), NIH grant RO1 DK087715 (to ROH), March of Dimes grant 6-FY15-235 (to ROH), and the Burroughs Wellcome Fund Clinical Scientist Award in Translational Research (grant 1008525) (to ROH). The Ts65Dn, Dyrk1a ${ }^{+/-}$animals were generated through support from the Indiana Clinical and Translational Sciences Institute with funding in part by grant UL1TR001108 from the NIH, National Center for Advancing Translational Sciences, Clinical and Translational Sciences Award (to RJR).

Address correspondence to: Robert O. Heuckeroth, Children's Hospital of Philadelphia Research Institute, Perelman School of Medicine at the University of Pennsylvania, Abramson Research Center, Suite 1116I, 3615 Civic Center Boulevard, Philadelphia, Pennsylvania 19104-4318, USA. Phone: 215.590.1209; Email: Heuckerothr@email.chop.edu.

1. Stoll C, Dott B, Alembik Y, Roth MP. Associated congenital anomalies among cases with Down syndrome. Eur J Med Genet. 2015;58(12):674-680.

2. Moore SW. Down syndrome and the enteric nervous system. Pediatr Surg Int. 2008;24(8):873-883.

3. Wallace RA. Clinical audit of gastrointestinal conditions occurring among adults with Down syndrome attending a specialist clinic. J Intellect Dev Disabil. 2007;32(1):45-50.

4. Lake JI, Heuckeroth RO. Enteric nervous system development: migration, differentiation, and disease. Am J Physiol Gastrointest Liver Physiol. 2013;305(1):G1-24.

5. Avetisyan M, Schill EM, Heuckeroth RO. Building a second brain in the bowel. J Clin Invest. 2015;125(3):899-907.

6. Schneider S, Wright CM, Heuckeroth RO. Unexpected Roles for the Second Brain: Enteric Nervous System as Master Regulator of Bowel Function. Annu Rev Physiol. 2019;81:235-259.

7. Espinosa-Medina I, et al. Dual origin of enteric neurons in vagal Schwann cell precursors and the sympathetic neural crest. Proc Natl Acad Sci USA. 2017;114(45):11980-11985.

8. Uesaka T, Nagashimada M, Enomoto H. Neuronal Differentiation in Schwann Cell Lineage Underlies Postnatal Neurogenesis in the Enteric Nervous System. J Neurosci. 2015;35(27):9879-9888.

9. Brokhman I, et al. Dual embryonic origin of the mammalian enteric nervous system. Dev Biol. 2019;445(2):256-270

10. Kulkarni S, et al. Adult enteric nervous system in health is maintained by a dynamic balance between neuronal apoptosis and neurogenesis. Proc Natl Acad Sci USA. 2017;114(18):E3709-E3718.

11. Jiang Y, Liu MT, Gershon MD. Netrins and DCC in the guidance of migrating neural crest-derived cells in the developing bowel and pancreas. Dev Biol. 2003;258(2):364-384.

12. Uesaka T, Nagashimada M, Enomoto H. GDNF signaling levels control migration and neuronal differentiation of enteric gan- 
glion precursors. J Neurosci. 2013;33(41):16372-16382.

13. Arshad A, Powell C, Tighe MP. Hirschsprung's disease. BMJ. 2012;345:e5521.

14. Friedmacher F, Puri P. Hirschsprung's disease associated with Down syndrome: a meta-analysis of incidence, functional outcomes and mortality. Pediatr Surg Int. 2013;29(9):937-946.

15. Arnold S, et al. Interaction between a chromosome 10 RET enhancer and chromosome 21 in the Down syndrome-Hirschsprung disease association. Hum Mutat. 2009;30(5):771-775.

16. Heuckeroth RO. Hirschsprung Disease. In: Faure C, Di Lorenzo C, Thapar N, ed. Pediatric Neurogastroenterology: Gastrointestinal Motility And Functional Disorders In Children. New York, NY: Springer; 2013:271-283.

17. Heuckeroth RO. Hirschsprung disease - integrating basic science and clinical medicine to improve outcomes. Nat Rev Gastroenterol Hepatol. 2018;15(3):152-167.

18. Jain S, et al. Mice expressing a dominant-negative Ret mutation phenocopy human Hirschsprung disease and delineate a direct role of Ret in spermatogenesis. Development. 2004;131(21):5503-5513.

19. Musser MA, Correa H, Southard-Smith EM. Enteric neuron imbalance and proximal dysmotility in ganglionated intestine of the intestine of the Sox10Dom/+ Hirschsprung mouse model. Cell Mol Gastroenterol Hepatol. 2015;1(1):87-101.

20. Menezes M, Puri P. Long-term outcome of patients with enterocolitis complicating Hirschsprung's disease. Pediatr Surg Int. 2006;22(4):316-318.

21. Travassos D, van Herwaarden-Lindeboom M, van der Zee DC. Hirschsprung's disease in children with Down syndrome: a comparative study. Eur J Pediatr Surg. 2011;21(4):220-223.

22. Quinn FM, Surana R, Puri P. The influence of trisomy 21 on outcome in children with Hirschsprung's disease. J Pediatr Surg. 1994;29(6):781-783.

23. Jannot AS, et al. Chromosome 21 scan in Down syndrome reveals DSCAM as a predisposing locus in Hirschsprung disease. PLoS One. 2013;8(5):e62519.

24. Korbel JO, et al. The genetic architecture of Down syndrome phenotypes revealed by high-resolution analysis of human seg mental trisomies. Proc Natl Acad Sci USA. 2009;106(29):12031-12036.

25. Yamakawa K, et al. DSCAM: a novel member of the immunoglobulin superfamily maps in a Down syndrome region and is involved in the development of the nervous system. Hum Mol Genet. 1998;7(2):227-237.

26. Wang Y, et al. Association between DSCAM polymorphisms and non-syndromic Hirschsprung disease in Chinese population. BMC Med Genet. 2018;19(1):116.

27. Ly A, Nikolaev A, Suresh G, Zheng Y, Tessier-Lavigne M, Stein E. DSCAM is a netrin receptor that collaborates with DCC in mediating turning responses to netrin-1. Cell. 2008;133(7):1241-1254.

28. Lai Wing Sun K, Correia JP, Kennedy TE. Netrins: versatile extracellular cues with diverse functions. Development. 2011;138(11):2153-2169.

29. Pontén F, Jirström K, Uhlen M. The Human Protein Atlas--a tool for pathology. J Pathol. 2008;216(4):387-393.

30. Visel A, Thaller C, Eichele G. GenePaint.org: an atlas of gene expression patterns in the mouse embryo. Nucleic Acids Res. 2004;32(Database issue):D552-D556.

31. Ehe BK, Lamson DR, Tarpley M, Onyenwoke RU, Graves LM, Williams KP. Identification of a DYRK1A-mediated phosphorylation site within the nuclear localization sequence of the hedgehog transcription factor GLI1. Biochem Biophys Res Commun. 2017;491(3):767-772

32. Liu JA, et al. Identification of GLI Mutations in Patients With Hirschsprung Disease That Disrupt Enteric Nervous System Development in Mice. Gastroenterology. 2015;149(7):1837-1848.e5.

33. Yang JT, Liu CZ, Villavicencio EH, Yoon JW, Walterhouse D, Iannaccone PM. Expression of human GLI in mice results in failure to thrive, early death, and patchy Hirschsprung-like gastrointestinal dilatation. Mol Med. 1997;3(12):826-835.

34. Najas S, et al. DYRK1A-mediated Cyclin D1 Degradation in Neural Stem Cells Contributes to the Neurogenic Cortical Defects in Down Syndrome. EBioMedicine. 2015;2(2):120-134.

35. Soppa U, Schumacher J, Florencio Ortiz V, Pasqualon T, Tejedor FJ, Becker W. The Down syndrome-related protein kinase DYRK1A phosphorylates p27(Kip1) and Cyclin D1 and induces cell cycle exit and neuronal differentiation. Cell Cycle. 2014;13(13):2084-2100.

36. Stagni F, Giacomini A, Emili M, Guidi S, Bartesaghi R. Neurogenesis impairment: An early developmental defect in Down syndrome. Free Radic Biol Med. 2018;114:15-32.

37. Reeves RH, et al. A mouse model for Down syndrome exhibits learning and behaviour deficits. Nat Genet. 1995;11(2):177-184

38. Gupta M, Dhanasekaran AR, Gardiner KJ. Mouse models of Down syndrome: gene content and consequences. Mamm Genome. 2016;27(11-12):538-555.

39. Williams AD, Mjaatvedt CH, Moore CS. Characterization of the cardiac phenotype in neonatal Ts65Dn mice. Dev Dyn 2008;237(2):426-435

40. Gutierrez-Castellanos N, Winkelman BH, Tolosa-Rodriguez L, Devenney B, Reeves RH, De Zeeuw CI. Size does not always matter: Ts65Dn Down syndrome mice show cerebellum-dependent motor learning deficits that cannot be rescued by postnatal SAG treatment. J Neurosci. 2013;33(39):15408-15413.

41. Trazzi S, Fuchs C, Valli E, Perini G, Bartesaghi R, Ciani E. The amyloid precursor protein (APP) triplicated gene impairs neuronal precursor differentiation and neurite development through two different domains in the Ts65Dn mouse model for Down syndrome. J Biol Chem. 2013;288(29):20817-20829.

42. Trazzi S, et al. APP-dependent up-regulation of Ptch1 underlies proliferation impairment of neural precursors in Down syndrome. Hum Mol Genet. 2011;20(8):1560-1573.

43. Contestabile A, Greco B, Ghezzi D, Tucci V, Benfenati F, Gasparini L. Lithium rescues synaptic plasticity and memory in Down syndrome mice. J Clin Invest. 2013;123(1):348-361.

44. Kida E, Rabe A, Walus M, Albertini G, Golabek AA. Long-term running alleviates some behavioral and molecular abnormalities in Down syndrome mouse model Ts65Dn. Exp Neurol. 2013;240:178-189.

45. Blazek JD, Billingsley CN, Newbauer A, Roper RJ. Embryonic and not maternal trisomy causes developmental attenuation in the Ts65Dn mouse model for Down syndrome. Dev Dyn. 2010;239(6):1645-1653. 
46. O'Doherty A, et al. An aneuploid mouse strain carrying human chromosome 21 with Down syndrome phenotypes. Science. 2005;309(5743):2033-2037.

47. Gribble SM, et al. Massively parallel sequencing reveals the complex structure of an irradiated human chromosome on a mouse background in the Tc1 model of Down syndrome. PLoS One. 2013;8(4):e60482.

48. Hosoda K, et al. Targeted and natural (piebald-lethal) mutations of endothelin-B receptor gene produce megacolon associated with spotted coat color in mice. Cell. 1994;79(7):1267-1276.

49. Soret R, et al. A collagen VI-dependent pathogenic mechanism for Hirschsprung's disease. J Clin Invest. 2015;125(12):4483-4496.

50. Roper RJ, St John HK, Philip J, Lawler A, Reeves RH. Perinatal loss of Ts65Dn Down syndrome mice. Genetics. 2006;172(1):437-443.

51. de Pontual L, et al. Epistatic interactions with a common hypomorphic RET allele in syndromic Hirschsprung disease. Hum Mutat. 2007;28(8):790-796.

52. Furness JB. Types of neurons in the enteric nervous system. J Auton Nerv Syst. 2000;81(1-3):87-96.

53. Wang $\mathrm{H}$, et al. The timing and location of glial cell line-derived neurotrophic factor expression determine enteric nervous system structure and function. J Neurosci. 2010;30(4):1523-1538.

54. Mongardi Fantaguzzi C, Thacker M, Chiocchetti R, Furness JB. Identification of neuron types in the submucosal ganglia of the mouse ileum. Cell Tissue Res. 2009;336(2):179-189.

55. Uesaka T, Young HM, Pachnis V, Enomoto H. Development of the intrinsic and extrinsic innervation of the gut. Dev Biol. 2016;417(2):158-167.

56. Pham TD, Gershon MD, Rothman TP. Time of origin of neurons in the murine enteric nervous system: sequence in relation to phenotype. J Comp Neurol. 1991;314(4):789-798.

57. Avetisyan M, et al. Hepatocyte Growth Factor and MET Support Mouse Enteric Nervous System Development, the Peristaltic Response, and Intestinal Epithelial Proliferation in Response to Injury. J Neurosci. 2015;35(33):11543-11558.

58. Foong JP, Tough IR, Cox HM, Bornstein JC. Properties of cholinergic and non-cholinergic submucosal neurons along the mouse colon. J Physiol (Lond). 2014;592(4):777-793.

59. Vanner S, Macnaughton WK. Submucosal secretomotor and vasodilator reflexes. Neurogastroenterol Motil. 2004;16 Suppl 1:39-43.

60. Swenson O, Bill AH. Resection of rectum and rectosigmoid with preservation of the sphincter for benign spastic lesions producing megacolon; an experimental study. Surgery. 1948;24(2):212-220.

61. Swenson O, Rheinlander HF, Diamond I. Hirschsprung's disease; a new concept of the etiology; operative results in 34 patients N Engl J Med. 1949;241(15):551-556.

62. Cammarata-Scalisi F, Paoli-Valeri M, Cammarata-Scalisi G, Díaz JJ, Nasre R, Cammarata-Scalisi ME. [Frequency of imperforate anus and associated risk factors in patients with Down syndrome]. Acta Gastroenterol Latinoam. 2012;42(1):40-45.

63. Freeman SB, et al. Congenital gastrointestinal defects in Down syndrome: a report from the Atlanta and National Down Syndrome Projects. Clin Genet. 2009;75(2):180-184

64. Deitz SL, Roper RJ. Trisomic and allelic differences influence phenotypic variability during development of Down syndrome mice. Genetics. 2011;189(4):1487-1495.

65. Das I, Reeves RH. The use of mouse models to understand and improve cognitive deficits in Down syndrome. Dis Model Mech 2011;4(5):596-606.

66. Currier DG, Polk RC, Reeves RH. A Sonic hedgehog (Shh) response deficit in trisomic cells may be a common denominator for multiple features of Down syndrome. Prog Brain Res. 2012;197:223-236.

67. Roper RJ, Baxter LL, Saran NG, Klinedinst DK, Beachy PA, Reeves RH. Defective cerebellar response to mitogenic Hedgehog signaling in Down [corrected] syndrome mice. Proc Natl Acad Sci USA. 2006;103(5):1452-1456.

68. Roper RJ, VanHorn JF, Cain CC, Reeves RH. A neural crest deficit in Down syndrome mice is associated with deficient mitotic response to Sonic hedgehog. Mech Dev. 2009;126(3-4):212-219.

69. Lake JI, Tusheva OA, Graham BL, Heuckeroth RO. Hirschsprung-like disease is exacerbated by reduced de novo GMP synthesis. J Clin Invest. 2013;123(11):4875-4887.

70. Yamagata M, Sanes JR. Dscam and Sidekick proteins direct lamina-specific synaptic connections in vertebrate retina. Nature. 2008;451(7177):465-469.

71. Fuerst PG, et al. DSCAM and DSCAML1 function in self-avoidance in multiple cell types in the developing mouse retina. Neuron. 2009;64(4):484-497.

72. Amano K, et al. DSCAM deficiency causes loss of pre-inspiratory neuron synchroneity and perinatal death. $J$ Neurosci. 2009;29(9):2984-2996

73. Yabut O, Domogauer J, D’Arcangelo G. Dyrk1A overexpression inhibits proliferation and induces premature neuronal differentiation of neural progenitor cells. J Neurosci. 2010;30(11):4004-4014.

74. Fattahi F, et al. Deriving human ENS lineages for cell therapy and drug discovery in Hirschsprung disease. Nature. 2016;531(7592):105-109.

75. Tang CS, et al. Identification of Genes Associated With Hirschsprung Disease, Based on Whole-Genome Sequence Analysis, and Potential Effects on Enteric Nervous System Development. Gastroenterology. 2018;155(6):1908-1922.e5.

76. Grossman TR, et al. Over-expression of DSCAM and COL6A2 cooperatively generates congenital heart defects. PLoS Genet. 2011;7(11):e1002344

77. Li JC, Mi KH, Zhou JL, Busch L, Kuhnel W. The development of colon innervation in trisomy 16 mice and Hirschsprung's disease. World J Gastroenterol. 2001;7(1):16-21.

78. Leffler A, Wedel T, Busch LC. Congenital colonic hypoganglionosis in murine trisomy 16--an animal model for Down's syndrome. Eur J Pediatr Surg. 1999;9(6):381-388

79. Walters LC, Cantrell VA, Weller KP, Mosher JT, Southard-Smith EM. Genetic background impacts developmental potential of enteric neural crest-derived progenitors in the Sox10Dom model of Hirschsprung disease. Hum Mol Genet. 2010;19(22):4353-4372.

80. Reinholdt LG, et al. Molecular characterization of the translocation breakpoints in the Down syndrome mouse model Ts65Dn. Mamm Genome. 2011;22(11-12):685-691.

81. Knowles $\mathrm{CH}$, et al. Quantitation of cellular components of the enteric nervous system in the normal human gastrointestinal 
tract--report on behalf of the Gastro 2009 International Working Group. Neurogastroenterol Motil. 2011;23(2):115-124.

82. Fotaki V, et al. Dyrk1A haploinsufficiency affects viability and causes developmental delay and abnormal brain morphology in mice. Mol Cell Biol. 2002;22(18):6636-6647.

83. Blazek JD, Abeysekera I, Li J, Roper RJ. Rescue of the abnormal skeletal phenotype in Ts65Dn Down syndrome mice using genetic and therapeutic modulation of trisomic Dyrk1a. Hum Mol Genet. 2015;24(20):5687-5696.

84. Enomoto H, Crawford PA, Gorodinsky A, Heuckeroth RO, Johnson EM, Milbrandt J. RET signaling is essential for migration, axonal growth and axon guidance of developing sympathetic neurons. Development. 2001;128(20):3963-3974.

85. Viader A, Wright-Jin EC, Vohra BP, Heuckeroth RO, Milbrandt J. Differential regional and subtype-specific vulnerability of enteric neurons to mitochondrial dysfunction. PLoS One. 2011;6(11):e27727.

86. Wright-Jin EC, Grider JR, Duester G, Heuckeroth RO. Retinaldehyde dehydrogenase enzymes regulate colon enteric nervous system structure and function. Dev Biol. 2013;381(1):28-37.

87. Vilz TO, Overhaus M, Stoffels B, Websky Mv, Kalff JC, Wehner S. Functional assessment of intestinal motility and gut wall inflammation in rodents: analyses in a standardized model of intestinal manipulation. J Vis Exp. 2012;(67):4086.

88. Sasselli V, Boesmans W, Vanden Berghe P, Tissir F, Goffinet AM, Pachnis V. Planar cell polarity genes control the connectivity of enteric neurons. J Clin Invest. 2013;123(4):1763-1772. 